\title{
Cytotoxic dinuclear titanium-salan complexes: Structural and biological characterization
}

\author{
Timo A. Immel, Martin Grützke, Ellen Batroff, Ulrich Groth, Thomas Huhn* \\ Fachbereich Chemie and Konstanz Research School Chemical Biology, Universität Konstanz, Universitätsstraße 10, Fach 720, 78457 Konstanz, Germany
}

\begin{abstract}
A B S T R A C T
Controlled hydrolysis of donor-substituted titanium-salan complexes led to the formation of well-defined dinuclear complexes. Structure determination by means of X-ray and NMR-studies revealed the presence of a single $\mu$-oxo bridge and one labile alkoxide ligand per titanium center. Concomitant cytotoxicity assays of the isolated dinuclear complexes showed cytotoxicities in the low micro-molar region, surpassing in this respect even their monomeric ancestors, thus making them possible highly active metabolites of titaniumsalan anti-cancer drugs.
\end{abstract}

Keywords:

Dinuclear complexes

Titanium salan complexes

Hydrolysis

Antitumor agents

Cytotoxicity

\section{Introduction}

Titanium complexes have attracted attention due to their encouraging antitumor activity in various cell lines. Today, with derivatives of titanocene dichloride $\left(\mathrm{Cp}_{2} \mathrm{TiCl}_{2}\right)$ [1-5], diketonato-complexes such as budotitane $\left[\mathrm{Ti}(\mathrm{bzac})_{2}(\mathrm{OEt})_{2} ; \quad\right.$ Hbzac $=$ Phenylbutane-1,3dione] [6-8] and titanium salan complexes ([ONNO]-type tetradentate diamine-diphenolato ligands) [9-11], three classes of cytotoxic titanium complexes are known. Whereas for cisplatin the mechanism of action is well understood, in the case of titanium complexes the nature of the active species is still unclear. Is partial hydrolysis of the labile ligands an activating mechanism, as in the cisplatin case, or does it lead to deactivation by the formation of non-toxic polynuclear oxo-titanium species?

The hydrolysis of budotitane and titanocene derivatives is very fast, often in the range of minutes yielding a multitude of metabolites $[12,13]$. Titanium salan complexes are remarkably different in this respect. Dependent on the nature of the phenolate substituents, hydrolysis rates were recently shown to vary between several minutes and more than $120 \mathrm{~h}$, with the size of the labile alkoxy ligand exerting a strong influence on overall cytotoxicity [14]. However, the attempted isolation or characterization of a bioactive intermediate from partial hydrolysis has so far proved unsuccessful; only a trinuclear $\mu_{2}$-oxo bridged titanium salan complex was described as being nontoxic $[15,16]$. With its lack of any labile ligand, it represents a species, where hydrolysis led ultimately to complete detoxification. Recently,

\footnotetext{
* Corresponding author. Tel.: + 497531 882283; fax: + 497531884424. E-mail address: thomas.huhn@uni-konstanz.de (T. Huhn).
}

Nielson and Waters reported the identification of $\mu$-oxo bridged dimeric complexes bearing a single alkoxide at each titanium center [17]. Unfortunately, their solubility was quite limited and in some cases even to low for NMR-measurements thus disqualifying those complexes for biological assays.

Herein we report the synthesis and structural characterization of a highly cytotoxic dinuclear titanium species, the first cytotoxic intermediate from partial hydrolysis of a titanium salan complex. By using methoxy residues at the aromatic rings, we dramatically enhanced the solubility of this class of dimeric complexes. Through this we could show that this intermediate is a potent cytotoxic agent itself, even surpassing its parent compound in terms of efficacy and might play an important role in the metabolism of titanium-salan complexes.

\section{Experimental}

\subsection{Materials and methods}

Titanium tetra(ethoxide) (99\%) and ethylenediamine (99\%) were purchased from ABCR GmbH (Karlsruhe, Germany), deuterated solvents were purchased from euriso-top (Saarbrücken, Germany) and dried where necessary; other solvents were purified according to standard procedures [18]. All experiments requiring dry atmosphere were carried out under nitrogen atmosphere using Schlenk technique. NMR data were recorded on JEOL Eclipse 400 and Bruker Avance DRX 600 spectrometers at the given frequencies. The ${ }^{1} \mathrm{H}$ and ${ }^{13} \mathrm{C}$ NMR chemical shifts are reported relative to tetramethylsilane; the resonance of the residual protons of the solvents served as internal standard for ${ }^{1} \mathrm{H}$ ( $\delta 7.15$ benzene; 7.26 chloroform) and the central 
signal of the solvent peaks for ${ }^{13} \mathrm{C}$ ( $\delta 128.0$ benzene; 77.0 chloroform $)$. The splitting of proton resonances in the reported ${ }^{1} \mathrm{H}$ NMR spectra is defined as $\mathrm{s}=$ singlet, $\mathrm{d}=$ doublet, $\mathrm{dd}=$ doublet of doublet, $\mathrm{m}=$ multiplet, $\mathrm{dq}=$ doublet of quartet and $\mathrm{t}=$ triplet. Structure assignments are based on 2D-NMR (COSY, HMBC, HSQC) experiments. Elemental analyses were performed in the microanalytical laboratory of the University of Konstanz.

\subsection{Synthesis of ligands $\mathrm{H}_{4} \mathrm{~L}^{1-3}$ via Schiff bases $\mathrm{SB}^{1-3}$}

The Schiff-bases $\mathrm{SB}^{1-3}$ were synthesized by stirring of the respective salicyl aldehydes ( $2 \mathrm{mmol}$ ) in methanol at room temperature and adding ethylenediamine ( $1 \mathrm{mmol}$ ) [19-22]. After $30 \mathrm{~min}$, the yellow $\mathrm{SB}^{1-3}$-precipitate was filtered off and suspended in methanol. After cooling to $0{ }^{\circ} \mathrm{C}, \mathrm{NaBH}_{4}(8 \mathrm{mmol})$ was added and the reaction mixture was stirred for $1 \mathrm{~h}$ at room temperature. After addition of water and extraction with dichloromethane, the organic layer was dried over $\mathrm{MgSO}_{4}$ and the solvents were evaporated. The resulting ligands $\mathrm{H}_{4} \mathrm{~L}^{1-3}$ could be used without further purification.

\subsection{1. $H_{4} L^{1}$}

$\mathrm{SB}^{1}$ was prepared according to the general procedure in a yield of $95 \% .{ }^{1} \mathrm{H}-\mathrm{NMR}\left(400 \mathrm{MHz}, \mathrm{CDCl}_{3}\right): \delta=3.87\left(\mathrm{~s}, 6 \mathrm{H}, \mathrm{OCH}_{3}\right), 3.94(\mathrm{~s}, 4 \mathrm{H}$, $\mathrm{NCH}_{2} \mathrm{CH}_{2} \mathrm{~N}$ ), $6.76\left(\mathrm{dd},{ }^{3} \mathrm{~J}_{1}={ }^{3} J_{2}=7.8 \mathrm{~Hz}, 2 \mathrm{H}, \mathrm{H}-\mathrm{Ar}\right.$ ), $6.83\left(\mathrm{dd},{ }^{3} \mathrm{~J}=\right.$ $\left.7.8 \mathrm{~Hz},{ }^{4} J=1.4 \mathrm{~Hz}, 2 \mathrm{H}, \mathrm{H}-\mathrm{Ar}\right), 6.89\left(\mathrm{dd},{ }^{3} J=7.8 \mathrm{~Hz},{ }^{4} \mathrm{~J}=1.4 \mathrm{~Hz}, 2 \mathrm{H}\right.$, $\mathrm{H}-\mathrm{Ar}), 8.31 \mathrm{ppm}(\mathrm{s}, 2 \mathrm{H}, \mathrm{N}=\mathrm{CH}) ;{ }^{13} \mathrm{C}-\mathrm{NMR}\left(101 \mathrm{MHz}, \mathrm{CDCl}_{3}\right)$ : $\delta=56.27\left(\mathrm{OCH}_{3}\right), 59.69\left(\mathrm{NCH}_{2} \mathrm{CH}_{2} \mathrm{~N}\right), 114.29(\mathrm{C}-\mathrm{Ar}), 118.26(\mathrm{C}-\mathrm{Ar})$, 118.61 (C-Ar), 123.31 (C-Ar), 148.49 (C-Ar), 151.63 (C-Ar), $166.87 \mathrm{ppm}(\mathrm{N}=\mathrm{CH}) ;$ m.p. $162.5-163.0{ }^{\circ} \mathrm{C}(\mathrm{MeOH}$, yellow crystals); elemental analysis calcd (\%) for $\mathrm{C}_{18} \mathrm{H}_{20} \mathrm{~N}_{2} \mathrm{O}_{4}$ : C 65.84, H 6.14, N 8.53; found: C 65.66, H 6.28, N 8.48.

$\mathrm{H}_{4} \mathrm{~L}^{1}$ was prepared from $\mathrm{SB}^{1}$ according to the general procedure in a yield of $90 \% .{ }^{1} \mathrm{H}-\mathrm{NMR}\left(400 \mathrm{MHz}, \mathrm{CDCl}_{3}\right): \delta=2.82\left(\mathrm{~s}, 4 \mathrm{H}, \mathrm{NCH}_{2}\right.$ $\mathrm{CH}_{2} \mathrm{~N}$ ), $3.87\left(\mathrm{~s}, 6 \mathrm{H}, \mathrm{OCH}_{3}\right.$ ), $3.99\left(\mathrm{~s}, 4 \mathrm{H}, \mathrm{NCH}_{2} \mathrm{C}-\mathrm{Ar}\right.$ ), $6.62\left(\mathrm{~d},{ }^{3} \mathrm{~J}=\right.$ $7.7 \mathrm{~Hz}, 2 \mathrm{H}, \mathrm{H}-\mathrm{Ar}$ ), $6.74\left(\mathrm{dd},{ }^{3} J_{1}={ }^{3} J_{2}=7.7 \mathrm{~Hz}, 2 \mathrm{H}, \mathrm{H}-\mathrm{Ar}\right.$ ), $6.81 \mathrm{ppm}$ (d, $\left.3^{3}=7.7 \mathrm{~Hz}, 2 \mathrm{H}, \mathrm{H}-\mathrm{Ar}\right) ;{ }^{13} \mathrm{C}-\mathrm{NMR}\left(101 \mathrm{MHz}, \mathrm{CDCl}_{3}\right): \delta=47.95$ $\left(\mathrm{NCH}_{2} \mathrm{CH}_{2} \mathrm{~N}\right), 52.12\left(\mathrm{OCH}_{3}\right), 56.13\left(\mathrm{NCH}_{2} \mathrm{C}-\mathrm{Ar}\right), 111.13(\mathrm{C}-\mathrm{Ar})$, 119.08 (C-Ar), 120.92 (C-Ar), 123.03 (C-Ar), 147.09 (C-Ar), $148.14 \mathrm{ppm}(\mathrm{C}-\mathrm{Ar}) ;$ m.p. $176{ }^{\circ} \mathrm{C}\left(\mathrm{CHCl}_{3} / \mathrm{MeOH}\right)$; elemental analysis calcd (\%) for $\mathrm{C}_{18} \mathrm{H}_{24} \mathrm{~N}_{2} \mathrm{O}_{4}$ : C 65.04, H 7.28, N 8.43; found: C 65.00, H $7.24, \mathrm{~N} 8.51$.

\subsection{2. $\mathrm{H}_{4} L^{2}$}

$\mathrm{SB}^{2}$ was prepared according to the general procedure in a yield of $95 \% .{ }^{1} \mathrm{H}-\mathrm{NMR}\left(400 \mathrm{MHz}, \mathrm{CDCl}_{3}\right): \delta=3.75\left(\mathrm{~s}, 6 \mathrm{H}, \mathrm{OCH}_{3}\right), 3.94(\mathrm{~s}, 4 \mathrm{H}$, $\mathrm{NCH}_{2} \mathrm{CH}_{2} \mathrm{~N}$ ), $6.73\left(\mathrm{dd},{ }^{3} \mathrm{~J}=2.7 \mathrm{~Hz},{ }^{4} \mathrm{~J}=0.6 \mathrm{~Hz}, 2 \mathrm{H}, \mathrm{H}-\mathrm{Ar}\right.$ ), $6.80-6.95$ $(\mathrm{m}, 4 \mathrm{H}, \mathrm{H}-\mathrm{Ar}), 8.31 \mathrm{ppm}(\mathrm{s}, 2 \mathrm{H}, \mathrm{N}=\mathrm{CH}) ;{ }^{13} \mathrm{C}-\mathrm{NMR}(101 \mathrm{MHz}$, $\left.\mathrm{CDCl}_{3}\right): \delta=56.14\left(\mathrm{OCH}_{3}\right), 60.05\left(\mathrm{NCH}_{2} \mathrm{CH}_{2} \mathrm{~N}\right), 115.16(\mathrm{C}-\mathrm{Ar})$, 117.89 (C-Ar), 118.46 (C-Ar), 119.75 (C-Ar), 152.25 (C-Ar), 155.36 ( C - Ar), 166.47 ppm ( $\mathrm{N}=\mathrm{CH})$; m.p. $164.5-165.0^{\circ} \mathrm{C}(\mathrm{MeOH}$, yellow crystals); elemental analysis calcd (\%) for $\mathrm{C}_{18} \mathrm{H}_{20} \mathrm{~N}_{2} \mathrm{O}_{4}$ : C 65.84, H 6.14, N 8.53; found: C 65.73, H 6.21, N 8.50.

$\mathrm{H}_{4} \mathrm{~L}^{2}$ was prepared from $\mathrm{SB}^{2}$ according to the general procedure in a yield of $80 \% .{ }^{1} \mathrm{H}-\mathrm{NMR}\left(400 \mathrm{MHz}, \mathrm{CDCl}_{3}\right): \delta=2.82\left(\mathrm{~s}, 4 \mathrm{H}, \mathrm{NCH}_{2}\right.$ $\left.\mathrm{CH}_{2} \mathrm{~N}\right), 3.74\left(\mathrm{~s}, 6 \mathrm{H}, \mathrm{OCH}_{3}\right), 3.95\left(\mathrm{~s}, 4 \mathrm{H}, \mathrm{NCH}_{2} \mathrm{C}-\mathrm{Ar}\right), 6.27\left(\mathrm{dd},{ }^{3} \mathrm{~J}=\right.$ $8.3 \mathrm{~Hz},{ }^{4} \mathrm{~J}=2.5 \mathrm{~Hz}, 2 \mathrm{H}, \mathrm{H}-\mathrm{Ar}$ ), 6.34 (d, ${ }^{4} \mathrm{~J}=2.5 \mathrm{~Hz}, 2 \mathrm{H}, \mathrm{H}-\mathrm{Ar}$ ), 6.79 (dd, ${ }^{3} \mathrm{~J}=8.3 \mathrm{~Hz}, 2 \mathrm{H}, \mathrm{H}-\mathrm{Ar}$ ), ppm; ${ }^{13} \mathrm{C}-\mathrm{NMR}\left(101 \mathrm{MHz}, \mathrm{CDCl}_{3}\right)$ : $\delta=48.09\left(\mathrm{NCH}_{2} \mathrm{CH}_{2} \mathrm{~N}\right), 52.92\left(\mathrm{OCH}_{3}\right), 56.01\left(\mathrm{NCH}_{2} \mathrm{C}-\mathrm{Ar}\right), 113.96$ (C-Ar), 114.60 (C-Ar), 117.00 (C-Ar), 123.03 (C-6), 151.91 (C-Ar), $152.80 \mathrm{ppm} \quad(\mathrm{C}-\mathrm{Ar}) ; \quad$ m.p. $\quad 155.0-155.5^{\circ} \mathrm{C} \quad\left(\mathrm{CHCl}_{3} / \mathrm{MeOH}\right)$; elemental analysis calcd (\%) for $\mathrm{C}_{18} \mathrm{H}_{24} \mathrm{~N}_{2} \mathrm{O}_{4}$ : C 65.04, H 7.28, N 8.43; found: C $64.63, \mathrm{H} 7.23, \mathrm{~N} 8.32$.

\subsection{3. $\mathrm{H}_{4} L^{3}$}

$\mathrm{SB}^{3}$ was prepared according to the general procedure in a yield of 69\%. 'H-NMR (400 MHz, $\left.\mathrm{CDCl}_{3}\right): \delta=3.79\left(\mathrm{~s}, 6 \mathrm{H}, \mathrm{OCH}_{3}\right), 3.89(\mathrm{~s}, 4 \mathrm{H}$,
$\left.\mathrm{NCH}_{2} \mathrm{CH}_{2} \mathrm{~N}\right), 6.27\left(\mathrm{~d},{ }^{3} \mathrm{~J}=8.4 \mathrm{~Hz}, 2 \mathrm{H}, \mathrm{H}-\mathrm{Ar}\right), 6.52\left(\mathrm{~d},{ }^{3} \mathrm{~J}=8.4 \mathrm{~Hz}, 2 \mathrm{H}\right.$, $\mathrm{H}-\mathrm{Ar}), 7.20\left(\mathrm{dd},{ }^{3} J_{1}={ }^{3} J_{2}=8.4 \mathrm{~Hz}, 2 \mathrm{H}, \mathrm{H}-\mathrm{Ar}\right), 8.80 \mathrm{ppm}(\mathrm{s}, 2 \mathrm{H}$, $\mathrm{N}=\mathrm{CH}) ;{ }^{13} \mathrm{C}$-NMR $\left(101 \mathrm{MHz}, \mathrm{CDCl}_{3}\right): \delta=55.77\left(\mathrm{OCH}_{3}\right), 59.75\left(\mathrm{NCH}_{2}\right.$ $\left.\mathrm{CH}_{2} \mathrm{~N}\right), 99.96(\mathrm{C}-\mathrm{Ar}), 108.26(\mathrm{C}-\mathrm{Ar}), 110.44(\mathrm{C}-\mathrm{Ar}), 133.66$ (C-Ar), $159.82(\mathrm{C}-\mathrm{Ar}), 162.82(\mathrm{~N}=\mathrm{CH}), 163.99 \mathrm{ppm}(\mathrm{C}-\mathrm{Ar}) ;$ m.p. $128.5-129.5^{\circ} \mathrm{C}(\mathrm{MeOH}$, yellow crystals); elemental analysis calcd (\%) for $\mathrm{C}_{18} \mathrm{H}_{20} \mathrm{~N}_{2} \mathrm{O}_{4}$ : C 65.84, H 6.14, N 8.53; found: C 65.70, H 6.16, N 8.49 .

$\mathrm{H}_{4} \mathrm{~L}^{3}$ was prepared from $\mathrm{SB}^{3}$ according to the general procedure in a yield of $95 \%$. ${ }^{1} \mathrm{H}-\mathrm{NMR}\left(400 \mathrm{MHz}, \mathrm{CDCl}_{3}\right): \delta=2.85\left(\mathrm{~s}, 4 \mathrm{H}, \mathrm{NCH}_{2} \mathrm{CH}_{2} \mathrm{~N}\right)$, $3.76\left(\mathrm{~s}, 6 \mathrm{H}, \mathrm{OCH}_{3}\right), 4.08\left(\mathrm{~s}, 4 \mathrm{H}, \mathrm{NCH}_{2} \mathrm{C}-\mathrm{Ar}\right), 6.37\left(\mathrm{~d},{ }^{3} \mathrm{~J}=8.2 \mathrm{~Hz}, 2 \mathrm{H}\right.$, $\mathrm{H}-\mathrm{Ar}), 6.47\left(\mathrm{~d},{ }^{3} \mathrm{~J}=8.2 \mathrm{~Hz}, 2 \mathrm{H}, \mathrm{H}-\mathrm{Ar}\right), 7.09 \mathrm{ppm}\left(\mathrm{dd},{ }^{3} J_{1}=\right.$ $\left.3_{2}=8.2 \mathrm{~Hz}, 2 \mathrm{H}, \mathrm{H}-\mathrm{Ar}\right) ;{ }^{13} \mathrm{C}-\mathrm{NMR}\left(101 \mathrm{MHz}, \mathrm{CDCl}_{3}\right): \delta=45.09$ $\left(\mathrm{NCH}_{2} \mathrm{CH}_{2} \mathrm{~N}\right), 48.15\left(\mathrm{OCH}_{3}\right), 55.71\left(\mathrm{NCH}_{2} \mathrm{C}-\mathrm{Ar}\right), 101.73(\mathrm{C}-\mathrm{Ar})$, 109.90 (C-Ar), 110.07 (C-Ar), 128.84 (C-Ar), 157.86 (C-Ar), $159.71 \mathrm{ppm}(\mathrm{C}-\mathrm{Ar})$; m.p. $146{ }^{\circ} \mathrm{C}\left(\mathrm{CH}_{2} \mathrm{Cl}_{2} / \mathrm{MeOH}\right)$; elemental analysis calcd (\%) for $\mathrm{C}_{18} \mathrm{H}_{24} \mathrm{~N}_{2} \mathrm{O}_{4}$ : C 65.04, H 7.28, N 8.43; found: C 64.99, $\mathrm{H}$ $7.21, \mathrm{~N} 8.43$.

\subsection{Synthesis of ligands $\mathrm{H}_{2} \mathrm{~L}^{1-3}$}

Ligands $\mathrm{H}_{4} \mathrm{~L}^{1-3}(10 \mathrm{mmol})$ were dissolved in acetonitrile/acetic acid (9: $1,200 \mathrm{ml})$. Formaldehyde $\left(37 \%\right.$ in $\mathrm{H}_{2} \mathrm{O}, 9 \mathrm{ml}$ ) was added and the reaction mixture was stirred for $1 \mathrm{~h}$ at room temperature. After cooling to $0{ }^{\circ} \mathrm{C}, \mathrm{NaBH}_{4}(40 \mathrm{mmol})$ was added in small portions. The mixture was allowed to warm to room temperature and stirred for additional $2 \mathrm{~h}$, solvents were evaporated and the remainder suspended in water. After adjusting to $\mathrm{pH} 6$, dichloromethane was added and the aqueous layer was extracted twice. The combined organic layers were dried over $\mathrm{MgSO}_{4}$, the solvent was evaporated and the resulting crude product recrystallized from ethanol. Ligands $\mathrm{H}_{2} \mathrm{~L}^{1,2}$ were already synthesized using an alternative approach [23, 24].

\subsection{1. $\mathrm{H}_{2} L^{1}$}

This compound was prepared according to the general procedure in a yield of $85 \%$. ${ }^{1} \mathrm{H}-\mathrm{NMR}\left(400 \mathrm{MHz}, \mathrm{CDCl}_{3}\right): \delta=2.30\left(\mathrm{~s}, 6 \mathrm{H}, \mathrm{NCH}_{3}\right)$, 2.70 (s, 4H, $\mathrm{NCH}_{2} \mathrm{CH}_{2} \mathrm{~N}$ ), $3.70\left(\mathrm{~s}, 4 \mathrm{H}, \mathrm{NCH}_{2} \mathrm{C}-\mathrm{Ar}\right), 3.86(\mathrm{~s}, 6 \mathrm{H}$, $\left.\mathrm{OCH}_{3}\right), 6.56\left(\mathrm{dd},{ }^{3} \mathrm{~J}=7.7 \mathrm{~Hz},{ }^{4} \mathrm{~J}=1.4 \mathrm{~Hz}, 2 \mathrm{H}, \mathrm{H}-\mathrm{Ar}\right), 6.72\left(\mathrm{dd},{ }^{3} J_{1}=\right.$ $\left.{ }^{3} J_{2}=7.7 \mathrm{~Hz}, 2 \mathrm{H}, \mathrm{H}-\mathrm{Ar}\right), 6.80 \mathrm{ppm}\left(\mathrm{dd},{ }^{3} \mathrm{~J}=7.7 \mathrm{~Hz},{ }^{4} \mathrm{~J}=1.4 \mathrm{~Hz}, 2 \mathrm{H}\right.$, $\mathrm{H}-\mathrm{Ar}) ;{ }^{13} \mathrm{C}-\mathrm{NMR}\left(101 \mathrm{MHz}, \mathrm{CDCl}_{3}\right): \delta=42.09\left(\mathrm{NCH}_{3}\right), 54.62\left(\mathrm{NCH}_{2}\right.$ $\left.\mathrm{CH}_{2} \mathrm{~N}\right), 56.10\left(\mathrm{NCH}_{2} \mathrm{C}-\mathrm{Ar}\right), 61.52\left(\mathrm{OCH}_{3}\right), 111.42(\mathrm{C}-\mathrm{Ar}), 119.01$ (C-Ar), 120.81 (C-Ar), 122.04 (C-Ar), 147.21 (C-Ar), $148.13 \mathrm{ppm}$ (C-Ar); m.p. $115.0-116.0^{\circ} \mathrm{C}$ (EtOH, colorless crystals); elemental analysis calcd (\%) for $\mathrm{C}_{20} \mathrm{H}_{28} \mathrm{~N}_{2} \mathrm{O}_{4}$ : $\mathrm{C} 66.64, \mathrm{H} \mathrm{7.83,N} \mathrm{7.77;} \mathrm{found:} \mathrm{C}$ $66.53, \mathrm{H} 7.80, \mathrm{~N} 7.75$.

\subsection{2. $\mathrm{H}_{2} L^{2}$}

This compound was prepared according to the general procedure in a yield of $80 \%$. ${ }^{1} \mathrm{H}-\mathrm{NMR}\left(400 \mathrm{MHz}, \mathrm{CDCl}_{3}\right): \delta=2.27\left(\mathrm{~s}, 6 \mathrm{H}, \mathrm{NCH}_{3}\right)$, 2.65 (s, 4H, $\mathrm{NCH}_{2} \mathrm{CH}_{2} \mathrm{~N}$ ), 3.65 (s, $4 \mathrm{H}, \mathrm{NCH}_{2} \mathrm{C}-\mathrm{Ar}$ ), 3.73 (s, $6 \mathrm{H}$, $\left.\mathrm{OCH}_{3}\right), 6.53\left(\mathrm{~d},{ }^{4} \mathrm{~J}=2.8 \mathrm{~Hz}, 2 \mathrm{H}, \mathrm{H}-\mathrm{Ar}\right), 6.73\left(\mathrm{dd},{ }^{3} \mathrm{~J}=8.7 \mathrm{~Hz},{ }^{4} \mathrm{~J}=\right.$ $2.8 \mathrm{~Hz}, 2 \mathrm{H}, \mathrm{H}-\mathrm{Ar}), 6.77 \mathrm{ppm}\left(\mathrm{d},{ }^{3} J=8.7 \mathrm{~Hz}, 2 \mathrm{H}, \mathrm{H}-\mathrm{Ar}\right) ;{ }^{13} \mathrm{C}-\mathrm{NMR}$ $\left(101 \mathrm{MHz}, \mathrm{CDCl}_{3}\right): \delta=41.93\left(\mathrm{NCH}_{3}\right), 54.29\left(\mathrm{NCH}_{2} \mathrm{CH}_{2} \mathrm{~N}\right), 55.91$ $\left(\mathrm{NCH}_{2} \mathrm{C}-\mathrm{Ar}\right), 62.02\left(\mathrm{OCH}_{3}\right), 113.86(\mathrm{C}-\mathrm{Ar}), 114.61(\mathrm{C}-\mathrm{Ar}), 116.77$ (C-Ar), 122.49 (C-Ar), 151.70 (C-Ar), 152.68 ppm (C-Ar); m.p. $149.0-150.0{ }^{\circ} \mathrm{C}$ (EtOH, colorless crystals); elemental analysis calcd (\%) for $\mathrm{C}_{20} \mathrm{H}_{28} \mathrm{~N}_{2} \mathrm{O}_{4}$ : C 66.64, H 7.83, N 7.77; found: C 66.63, H 7.94, N 7.72 .

\subsection{3. $\mathrm{H}_{2} \mathrm{~L}^{3}$}

This compound was prepared according to the general procedure in a yield of $28 \%$. The product was purified by flash chromatography on silica gel using ethyl acetate with an increasing gradient of ethanol. Recrystallization from ethanol gave analytical pure samples. 
${ }^{1} \mathrm{H}-\mathrm{NMR}\left(400 \mathrm{MHz}, \mathrm{CDCl}_{3}\right): \delta=2.30\left(\mathrm{~s}, 6 \mathrm{H}, \mathrm{NCH}_{3}\right), 2.68(\mathrm{~s}, 4 \mathrm{H}$, $\mathrm{NCH}_{2} \mathrm{CH}_{2} \mathrm{~N}$ ), $3.77\left(\mathrm{~s}, 6 \mathrm{H}, \mathrm{OCH}_{3}\right), 3.80\left(\mathrm{~s}, 4 \mathrm{H}, \mathrm{NCH}_{2} \mathrm{C}-\mathrm{Ar}\right), 6.36$ (dd, $\left.{ }^{3} J=8.3 \mathrm{~Hz},{ }^{4} J=0.7 \mathrm{~Hz}, 2 \mathrm{H}, \mathrm{H}-\mathrm{Ar}\right), 6.47\left(\mathrm{dd},{ }^{3} \mathrm{~J}=8.3 \mathrm{~Hz},{ }^{4} \mathrm{~J}=0.7 \mathrm{~Hz}\right.$, $2 \mathrm{H}, \mathrm{H}-\mathrm{Ar}), 7.09 \mathrm{ppm}\left(\mathrm{dd},{ }^{3} J_{1}={ }^{3} J_{2}=8.3 \mathrm{~Hz}, 2 \mathrm{H}, \mathrm{H}-\mathrm{Ar}\right) ;{ }^{13} \mathrm{C}-\mathrm{NMR}$ $\left(101 \mathrm{MHz}, \mathrm{CDCl}_{3}\right): \delta=42.11\left(\mathrm{NCH}_{3}\right), 54.41\left(\mathrm{NCH}_{2} \mathrm{CH}_{2} \mathrm{~N}, \mathrm{NCH}_{2} \mathrm{C}-\mathrm{Ar}\right)$, $55.68\left(\mathrm{OCH}_{3}\right), 101.62(\mathrm{C}-\mathrm{Ar}), 109.46(\mathrm{C}-\mathrm{Ar}), 109.69(\mathrm{C}-\mathrm{Ar}), 128.81$ (C-Ar), $157.98(\mathrm{C}-\mathrm{Ar}), 159.60 \mathrm{ppm}(\mathrm{C}-\mathrm{Ar}) ;$ m.p. $124.0-125.5^{\circ} \mathrm{C}$ (EtOH, colorless crystals); elemental analysis calcd (\%) for $\mathrm{C}_{20} \mathrm{H}_{28} \mathrm{~N}_{2} \mathrm{O}_{4}$ : C 66.64, H 7.83, N 7.77; found: C 66.58, H 7.82, N 7.79.

\subsection{Synthesis of mononuclear complexes $\left[\mathrm{TiL}^{1-3}(\mathrm{OEt})_{2}\right]$}

Ligands $\mathrm{H}_{2} \mathrm{~L}^{1-3}(1.5 \mathrm{mmol})$ were dissolved in toluene $(10 \mathrm{ml})$ and titanium ethoxide $(1.5 \mathrm{mmol})$ was added over $10 \mathrm{~min}$ under a nitrogen atmosphere [14]. The yellow reaction mixture was allowed to stir overnight at room temperature. After removal of the solvent under reduced pressure, the complex was obtained as yellow solid in nearly quantitative yield. Recrystallization from the given solvent gave analytical pure samples.

\subsection{1. $\left[\operatorname{TiL}^{1}(\mathrm{OEt})_{2}\right]$}

This compound was prepared according to the general procedure in a yield of $68 \% .{ }^{1} \mathrm{H}-\mathrm{NMR}\left(600 \mathrm{MHz}, \mathrm{CDCl}_{3}\right): \delta=1.28\left(\mathrm{t},{ }^{3} \mathrm{~J}=7 \mathrm{~Hz}\right.$, $\left.6 \mathrm{H}, \mathrm{OCH}_{2} \mathrm{CH}_{3}\right), 1.81\left(\mathrm{~d},{ }^{2} \mathrm{~J}=9.4 \mathrm{~Hz}, 2 \mathrm{H}, \mathrm{NCH}_{2} \mathrm{CH}_{2} \mathrm{~N}\right), 2.45(\mathrm{~s}, 6 \mathrm{H}$, $\left.\mathrm{NCH}_{3}\right), 2.98\left(\mathrm{~d},{ }^{2} \mathrm{~J}=9.4 \mathrm{~Hz}, 2 \mathrm{H}, \mathrm{NCH}_{2} \mathrm{CH}_{2} \mathrm{~N}\right), 3.14\left(\mathrm{~d},{ }^{2} \mathrm{~J}=13.5 \mathrm{~Hz}\right.$, $\left.2 \mathrm{H}, \mathrm{NCH}_{2} \mathrm{C}-\mathrm{Ar}\right), 3.85\left(\mathrm{~s}, 6 \mathrm{H}, \mathrm{OCH}_{3}\right), 4.59\left(\mathrm{~d},{ }^{2} J=13.5 \mathrm{~Hz}, 2 \mathrm{H}\right.$, $\mathrm{NCH}_{2} \mathrm{C}-\mathrm{Ar}$ ), $4.61\left(\mathrm{dq},{ }^{3} \mathrm{~J}=7 \mathrm{~Hz},{ }^{2} \mathrm{~J}=10.8 \mathrm{~Hz}, 2 \mathrm{H}, \mathrm{OCH}_{2}\right), 4.72$ (dq, $\left.{ }^{3} J=7 \mathrm{~Hz},{ }^{2} J=10.8 \mathrm{~Hz}, 2 \mathrm{H}, \mathrm{OCH}_{2}\right), 6.60\left(\mathrm{dd},{ }^{3} \mathrm{~J}=7.7 \mathrm{~Hz},{ }^{4} \mathrm{~J}=1.3 \mathrm{~Hz}\right.$, $2 \mathrm{H}, \mathrm{H}-\mathrm{Ar}$ ), $6.65\left(\mathrm{dd},{ }^{3} J_{1}={ }^{3} J_{2}=7.7 \mathrm{~Hz}, 2 \mathrm{H}, \mathrm{H}-\mathrm{Ar}\right.$ ), $6.83 \mathrm{ppm}(\mathrm{dd}$, $\left.{ }^{3} J=7.7 \mathrm{~Hz},{ }^{4} \mathrm{~J}=1.3 \mathrm{~Hz}, 2 \mathrm{H}, \mathrm{H}-\mathrm{Ar}\right) ;{ }^{13} \mathrm{C}-\mathrm{NMR}\left(151 \mathrm{MHz}, \mathrm{CDCl}_{3}\right)$ : $\delta=19.39\left(\mathrm{OCH}_{2} \mathrm{CH}_{3}\right), 47.33\left(\mathrm{NCH}_{3}\right), 52.11\left(\mathrm{NCH}_{2} \mathrm{CH}_{2} \mathrm{~N}\right), 56.72$ $(\mathrm{C}-\mathrm{Ar}), 64.35\left(\mathrm{NCH}_{2} \mathrm{C}-\mathrm{Ar}\right), 71.74\left(\mathrm{OCH}_{2} \mathrm{CH}_{3}\right), 113.13(\mathrm{C}-\mathrm{Ar})$, 117.69 (C-Ar), 122.14 (C-Ar), 125.50 (C-Ar), 148.58 (C-Ar), $152.01 \mathrm{ppm} \quad(\mathrm{C}-\mathrm{Ar}) ; \quad \mathrm{UV} / \mathrm{Vis} \quad\left(\mathrm{CHCl}_{3}\right): \lambda_{\max }(\varepsilon)=332 \mathrm{~nm}$ $\left(8859 \mathrm{M}^{-1} \mathrm{~cm}^{-1}\right) ;$ IR (ATR (Attenuated Total Reflectance)): $v=3058.52$ (w (weak)), 3012.47 (w), $2966.09(w), 2832.14(w)$, 1572.30 (m (medium)), 1483.38 (m), 1371.35 (m), 1301.80 (m), 1243.56 (s (strong)), 1083.33 (s), 1056.49 (s), 1005.67 (m), 905.36 (m), 865.69 (s), 811.18 (m), 765.81 (m) $723.43 \mathrm{~cm}^{-1}$ (s); m.p. 148.0-148.5 ${ }^{\circ} \mathrm{C}$ (EtOH, yellow prisms); elemental analysis calcd (\%) for $\mathrm{C}_{24} \mathrm{H}_{36} \mathrm{~N}_{2} \mathrm{O}_{6}$ Ti: C 58.07, H 7.31, N 5.64; found: C 58.05, H 7.38, N 5.65.

\subsection{2. $\operatorname{TiL}^{2}(\mathrm{OEt})_{2}$}

This compound was prepared according to the general procedure in a yield of $51 \%$. ${ }^{1} \mathrm{H}-\mathrm{NMR}\left(400 \mathrm{MHz}, \mathrm{CDCl}_{3}\right): \delta=1.25\left(\mathrm{t},{ }^{3} \mathrm{~J}=7 \mathrm{~Hz}\right.$, $\left.6 \mathrm{H}, \mathrm{OCH}_{2} \mathrm{CH}_{3}\right), 1.80\left(\mathrm{~d},{ }^{2} \mathrm{~J}=9.3 \mathrm{~Hz}, 2 \mathrm{H}, \mathrm{NCH}_{2} \mathrm{CH}_{2} \mathrm{~N}\right), 2.46(\mathrm{~s}, 6 \mathrm{H}$ $\left.\mathrm{NCH}_{3}\right), 2.99\left(\mathrm{~d},{ }^{2} J=9.3 \mathrm{~Hz}, 2 \mathrm{H}, \mathrm{NCH}_{2} \mathrm{CH}_{2} \mathrm{~N}\right), 3.08\left(\mathrm{~d},{ }^{2} J=13.6 \mathrm{~Hz}\right.$, $\left.2 \mathrm{H}, \mathrm{NCH}_{2} \mathrm{C}-\mathrm{Ar}\right), 3.74\left(\mathrm{~s}, 6 \mathrm{H}, \mathrm{OCH}_{3}\right), 4.48-4.60(\mathrm{~m}, 6 \mathrm{H}, \mathrm{H}-8$, $\left.\mathrm{OCH}_{2} \mathrm{CH}_{3}\right), 6.54\left(\mathrm{~d},{ }^{4} \mathrm{~J}=3.0 \mathrm{~Hz}, 2 \mathrm{H}, \mathrm{H}-\mathrm{Ar}\right), 6.67\left(\mathrm{~d},{ }^{3} \mathrm{~J}=8.8 \mathrm{~Hz}, 2 \mathrm{H}\right.$, $\mathrm{H}-\mathrm{Ar}), 6.74 \mathrm{ppm}\left(\mathrm{dd},{ }^{4} J=3.0 \mathrm{~Hz},{ }^{3} J=8.8 \mathrm{~Hz}, 2 \mathrm{H}, \mathrm{H}-\mathrm{Ar}\right) ;{ }^{13} \mathrm{C}-\mathrm{NMR}$ $\left(101 \mathrm{MHz}, \quad \mathrm{CDCl}_{3}\right): \delta=19.52\left(\mathrm{OCH}_{2} \mathrm{CH}_{3}\right), 47.40\left(\mathrm{NCH}_{3}\right), 52.10$ $\left(\mathrm{NCH}_{2} \mathrm{CH}_{2} \mathrm{~N}\right), 56.00\left(\mathrm{OCH}_{3}\right), 64.58\left(\mathrm{NCH}_{2} \mathrm{C}-\mathrm{Ar}\right), 71.54\left(\mathrm{OCH}_{2} \mathrm{CH}_{3}\right)$ 114.26 (C-Ar), 115.37 (C-Ar), 118.07 (C-Ar), 125.23 (C-Ar), $151.90(\mathrm{C}-\mathrm{Ar}), 155.88 \mathrm{ppm}(\mathrm{C}-\mathrm{Ar}) ; \mathrm{UV} / \mathrm{Vis}\left(\mathrm{CHCl}_{3}\right): \lambda_{\max }(\varepsilon)=$ $312 \mathrm{~nm}\left(12,139 \mathrm{M}^{-1} \mathrm{~cm}^{-1}\right)$; IR (ATR): $v=3013.72(\mathrm{w}), 2964.96$ (w), 2899.87 (w), 2831.35 (w), 1486.31 (s), 1413.60 (m), 1369.74 (w), 1316.46 (w), 1258.79 (s), 1223.05 (s), 1148.95 (m), 1110.87 $(\mathrm{m}), 1045.56(\mathrm{~s}), 1004.86(\mathrm{~s}), 904.67(\mathrm{~s}), 859.64(\mathrm{~s}), 824.68(\mathrm{~s})$, $799.21(\mathrm{~s}), \quad 752.71(\mathrm{~s}), 669.66 \mathrm{~cm}^{-1}(\mathrm{~m}) ;$ m.p. $160.0-161.0^{\circ} \mathrm{C}$ (EtOH, yellow prisms); elemental analysis calcd (\%) for $\mathrm{C}_{24} \mathrm{H}_{36} \mathrm{~N}_{2} \mathrm{O}_{6}$ Ti: C 58.07, H 7.31, N 5.64; found: C 57.94, H 7.16, N 5.68.

\subsection{3. $\operatorname{TiL}^{3}(\mathrm{OEt})_{2}$}

This compound was prepared according to the general procedure in a yield of $42 \%$. ${ }^{1} \mathrm{H}-\mathrm{NMR}\left(400 \mathrm{MHz}, \mathrm{C}_{6} \mathrm{D}_{6}\right): \delta=1.11\left(\mathrm{~d},{ }^{2} \mathrm{~J}=9.3 \mathrm{~Hz}\right.$, $\left.2 \mathrm{H}, \mathrm{NCH}_{2} \mathrm{CH}_{2} \mathrm{~N}\right), 1.28\left(\mathrm{t},{ }^{3} \mathrm{~J}=7.0 \mathrm{~Hz}, 6 \mathrm{H}, \mathrm{OCH}_{2} \mathrm{CH}_{3}\right), 2.27(\mathrm{~s}, 6 \mathrm{H}$, $\left.\mathrm{NCH}_{3}\right), 2.72\left(\mathrm{~d},{ }^{2} \mathrm{~J}=9.3 \mathrm{~Hz}, 2 \mathrm{H}, \mathrm{NCH}_{2} \mathrm{CH}_{2} \mathrm{~N}\right), 3.41\left(\mathrm{~s}, 6 \mathrm{H}, \mathrm{OCH}_{3}\right), 3.84$ $\left(\mathrm{d},{ }^{2} \mathrm{~J}=14.1 \mathrm{~Hz}, 2 \mathrm{H}, \quad \mathrm{NCH}_{2} \mathrm{C}-\mathrm{Ar}\right), 4.25 \quad\left(\mathrm{~d},{ }^{2} \mathrm{~J}=14.1 \mathrm{~Hz}, 2 \mathrm{H}\right.$, $\mathrm{NCH}_{2} \mathrm{C}-\mathrm{Ar}$ ), $4.63\left(\mathrm{dq},{ }^{3} J=7.0 \mathrm{~Hz},{ }^{2} J=10.8 \mathrm{~Hz}, 4 \mathrm{H}, \mathrm{OCH}_{2} \mathrm{CH}_{3}\right), 4.66$ (dq, $\left.{ }^{3} J=7.0 \mathrm{~Hz},{ }^{2} J=10.8 \mathrm{~Hz}, 4 \mathrm{H}, \mathrm{OCH}_{2} \mathrm{CH}_{3}\right), 6.20\left(\mathrm{~d},{ }^{3} J=8.2 \mathrm{~Hz}, 2 \mathrm{H}, \mathrm{H}-\mathrm{Ar}\right)$, $6.61\left(\mathrm{~d},{ }^{3} \mathrm{~J}=8.2 \mathrm{~Hz}, \mathrm{H}-\mathrm{Ar}\right), 7.11 \mathrm{ppm}\left(\mathrm{dd},{ }^{3} J_{1}={ }^{3} J_{2}=8.2 \mathrm{~Hz}, 2 \mathrm{H}\right.$, $\mathrm{H}-\mathrm{Ar}) ;{ }^{13} \mathrm{C}-\mathrm{NMR}\left(101 \mathrm{MHz}, \mathrm{C}_{6} \mathrm{D}_{6}\right): \delta=20.03\left(\mathrm{OCH}_{2} \mathrm{CH}_{3}\right), 47.84$ $\left(\mathrm{NCH}_{3}\right), 52.07\left(\mathrm{NCH}_{2} \mathrm{CH}_{2} \mathrm{~N}\right), 55.50\left(\mathrm{OCH}_{3}\right), 56.81\left(\mathrm{NCH}_{2} \mathrm{C}-\mathrm{Ar}\right), 71.84$ $\left(\mathrm{OCH}_{2} \mathrm{CH}_{3}\right), 101.04$ (C- Ar), 112.00 (C-Ar), 112.93 (C-Ar), 129.00 (C-Ar), 159.03 (C-Ar), $163.79 \mathrm{ppm}(\mathrm{C}-\mathrm{Ar}) ; \mathrm{UV} / \mathrm{Vis}\left(\mathrm{CHCl}_{3}\right): \lambda_{\max }$ $(\varepsilon)=319 \mathrm{~nm}\left(32,048 \mathrm{M}^{-1} \mathrm{~cm}^{-1}\right) ;$ IR (ATR): $v=3064.81(\mathrm{w}), 2966.00$ (m), $2924.06(\mathrm{~m}), 2859.21(\mathrm{~s}), 2839.40(\mathrm{~s}), 1896.43(\mathrm{w}), 1793.23(\mathrm{w})$, 1591.15 (s), 1572.40 (s), 1460.87 (s), 1420.15 (m), $1371.96(\mathrm{~m})$, $1351.83(\mathrm{w}), 1298.60(\mathrm{~s}), 1275.98(\mathrm{~m}), 1242.72(\mathrm{~s}), 1196.83(\mathrm{w})$ 1089.45 (s), $1006.16(\mathrm{~m}), 965.89(\mathrm{~m}), 935.97(\mathrm{~m}), 909.88(\mathrm{~s}), 844.94$ (w), $752.97 \mathrm{~cm}^{-1}(\mathrm{~s})$; m.p. $163.0-164.0^{\circ} \mathrm{C}$ (EtOH, yellow prisms); elemental analysis calcd (\%) for $\mathrm{C}_{24} \mathrm{H}_{36} \mathrm{~N}_{2} \mathrm{O}_{6}$ Ti: C 58.07, H 7.31, N 5.64; found: C 58.03, H 7.57, N 5.74 .

\subsection{Synthesis of dinuclear complexes $\left[L^{1,3}(\mathrm{OEt}) \mathrm{Ti}-\mathrm{O}-\mathrm{Ti}(\mathrm{OEt}) \mathrm{L}^{1,3}\right]$}

Complexes $\left[\mathrm{TiL}^{1,3}(\mathrm{OEt})_{2}\right.$ ] were suspended in a mixture of ethanol/ water (95:5). The suspension was heated to $60{ }^{\circ} \mathrm{C}$ and a mixture of ethanol/water as before was added dropwise until the complexes had dissolved. The reaction mixture was kept for 2 days at room temperature; during that time the product crystallized as very thin yellow platelets which were filtered off and washed with cold ethanol.

\subsection{1. [L' $\left.L^{\prime}(O E t) T i-O-T i(O E t) L^{1}\right]$}

This compound was prepared according to the general procedure in a yield of $80 \%$. ${ }^{1} \mathrm{H}-\mathrm{NMR}\left(600 \mathrm{MHz}, \mathrm{C}_{6} \mathrm{D}_{6}\right): \delta=1.04\left(\mathrm{~d},{ }^{2} J=9.9 \mathrm{~Hz}\right.$ $\left.2 \mathrm{H}, \mathrm{NCH}_{2} \mathrm{CH}_{2} \mathrm{~N}\right), 1.17\left(\mathrm{t}, 3 \mathrm{~J}=7.0 \mathrm{~Hz}, 6 \mathrm{H}, \mathrm{OCH}_{2} \mathrm{CH}_{3}\right), 1.19\left(\mathrm{~d},{ }^{2} J=\right.$ $\left.9.9 \mathrm{~Hz}, 2 \mathrm{H}, \mathrm{NCH}_{2} \mathrm{CH}_{2} \mathrm{~N}\right), 2.17\left(\mathrm{~s}, 6 \mathrm{H}, \mathrm{NCH}_{3}\right), 2.71\left(\mathrm{~d},{ }^{2} \mathrm{~J}=13.4 \mathrm{~Hz}, 2 \mathrm{H}\right.$, $\left.\mathrm{NCH}_{2} \mathrm{C}-\mathrm{Ar}\right), 2.74-2.90\left(\mathrm{~m}, 4 \mathrm{H}, \mathrm{NCH}_{2} \mathrm{CH}_{2} \mathrm{~N}\right), 2.85\left(\mathrm{~s}, 6 \mathrm{H}, \mathrm{NCH}_{3}\right), 3.01$ $\left(\mathrm{d},{ }^{2} \mathrm{~J}=14.1 \mathrm{~Hz}, 2 \mathrm{H}, \mathrm{NCH}_{2} \mathrm{C}-\mathrm{Ar}\right), 3.55\left(\mathrm{~s}, 6 \mathrm{H}, \mathrm{OCH}_{3}\right), 3.65(\mathrm{~s}, 6 \mathrm{H}$ $\left.\mathrm{OCH}_{3}\right), 4.56\left(\mathrm{dq},{ }^{2} J=11.1 \mathrm{~Hz},{ }^{3} J=7.0 \mathrm{~Hz}, 2 \mathrm{H}, \mathrm{OCH}_{2} \mathrm{CH}_{3}\right), 4.62\left(\mathrm{~d},{ }^{2} J=\right.$ $\left.13.4 \mathrm{~Hz}, 2 \mathrm{H}, \quad \mathrm{NCH}_{2} \mathrm{C}-\mathrm{Ar}\right), 4.88\left(\mathrm{dq},{ }^{2} \mathrm{~J}=11.1 \mathrm{~Hz},{ }^{3} \mathrm{~J}=7.0 \mathrm{~Hz}, 2 \mathrm{H}\right.$, $\left.\mathrm{OCH}_{2} \mathrm{CH}_{3}\right), 5.83\left(\mathrm{~d},{ }^{2} \mathrm{~J}=14.1 \mathrm{~Hz}, 2 \mathrm{H}, \mathrm{NCH}_{2} \mathrm{C}-\mathrm{Ar}\right), 6.55\left(\mathrm{dd},{ }^{3} \mathrm{~J}=7.7 \mathrm{~Hz}\right.$, $\left.{ }^{4} J=1.8 \mathrm{~Hz}, 2 \mathrm{H}, \mathrm{H}-\mathrm{Ar}\right), 6.58\left(\mathrm{dd},{ }^{3} J=7.7 \mathrm{~Hz},{ }^{4} J=1.8 \mathrm{~Hz}, 2 \mathrm{H}, \mathrm{H}-\mathrm{Ar}\right.$ ), $6.66\left(\mathrm{t},{ }^{3} \mathrm{~J}=7.7 \mathrm{~Hz}, 2 \mathrm{H}, \mathrm{H}-\mathrm{Ar}\right), 6.75\left(\mathrm{t}, 3^{3}=7.7 \mathrm{~Hz}, 2 \mathrm{H}, \mathrm{H}-\mathrm{Ar}\right), 6.80$ $\left(\mathrm{dd},{ }^{3} \mathrm{~J}=7.7 \mathrm{~Hz},{ }^{4} \mathrm{~J}=1.8 \mathrm{~Hz}, 2 \mathrm{H}, \mathrm{H}-\mathrm{Ar}\right), 6.82 \mathrm{ppm}\left(\mathrm{dd},{ }^{3} \mathrm{~J}=7.7 \mathrm{~Hz}\right.$ $\left.{ }^{4} \mathrm{~J}=1.8 \mathrm{~Hz}, \quad 2 \mathrm{H}, \quad \mathrm{H}-\mathrm{Ar}\right) ; \quad{ }^{13} \mathrm{C}-\mathrm{NMR} \quad\left(151 \mathrm{MHz}, \quad \mathrm{C}_{6} \mathrm{D}_{6}\right): \delta=19.57$ $\left(\mathrm{OCH}_{2} \mathrm{CH}_{3}\right), 47.52\left(\mathrm{NCH}_{3}\right), 47.84\left(\mathrm{NCH}_{3}\right), 51.68\left(\mathrm{NCH}_{2} \mathrm{CH}_{2} \mathrm{~N}\right), 52.88$ $\left(\mathrm{NCH}_{2} \mathrm{CH}_{2} \mathrm{~N}\right), 55.73\left(\mathrm{OCH}_{3}\right), 57.25\left(\mathrm{OCH}_{3}\right), 64.97\left(\mathrm{NCH}_{2} \mathrm{C}-\mathrm{Ar}\right), 65.13$ $\left(\mathrm{NCH}_{2} \mathrm{C}-\mathrm{Ar}\right), 72.23\left(\mathrm{OCH}_{2} \mathrm{CH}_{3}\right), 112.31(\mathrm{C}-\mathrm{Ar}), 114.18(\mathrm{C}-\mathrm{Ar})$ 117.26 (C-Ar), 117.36 (C-Ar), 122.51 (C-Ar), 123.45 (C-Ar), 126.26 (C-Ar), 127.29 (C-Ar), 149.17 (C-Ar), 149.64 (C-Ar), $153.17(\mathrm{C}-\mathrm{Ar}), 153.94 \mathrm{ppm}(\mathrm{C}-\mathrm{Ar}) ; \mathrm{UV} / \mathrm{Vis}\left(\mathrm{CHCl}_{3}\right): \lambda_{\max }(\varepsilon)=343$ (11,069), $240 \mathrm{~nm}\left(19,606 \mathrm{M}^{-1} \mathrm{~cm}^{-1}\right)$; IR (ATR): $v=2976.21(\mathrm{~s})$, 2849.26 (s), 2282.61 (w), $2050.20(w), 1980.69$ (w), 1593.26 (s), 1573.92 (s), 1462.45 (m), $1373.04(\mathrm{~m}), 1299.24(\mathrm{~s}), 1242.31$ (s), 1144.58 (m), $1088.57(\mathrm{~s}), 1008.03(\mathrm{~s}), 908.74(\mathrm{~m}), 751.65$ (s), $706.64 \mathrm{~cm}^{-1}$ (s); m.p. $210^{\circ} \mathrm{C}$ (EtOH, yellow rods); elemental analysis calcd (\%) for $\mathrm{C}_{44} \mathrm{H}_{62} \mathrm{~N}_{4} \mathrm{O}_{11}$ Ti: C 57.52, H 6.80, N 6.10; found: C 57.54, H $6.73, \mathrm{~N} 6.08$.

\subsection{2. $\left[L^{3}(O E t) T i-O-T i(O E t) L^{3}\right]$}

This compound was prepared according to the general procedure in a yield of $85 \% .{ }^{1} \mathrm{H}-\mathrm{NMR}\left(400 \mathrm{MHz}, \mathrm{C}_{6} \mathrm{D}_{6}\right): \delta=1.04\left(\mathrm{~d},{ }^{2} J=9.7 \mathrm{~Hz}\right.$, $\left.2 \mathrm{H}, \mathrm{NCH}_{2} \mathrm{CH}_{2} \mathrm{~N}\right), 1.13\left(\mathrm{t},{ }^{3} \mathrm{~J}=7.0 \mathrm{~Hz}, 6 \mathrm{H}, \mathrm{OCH}_{2} \mathrm{CH}_{3}\right), 1.15\left(\mathrm{~d},{ }^{2} \mathrm{~J}=\right.$ $\left.9.7 \mathrm{~Hz}, 2 \mathrm{H}, \mathrm{NCH}_{2} \mathrm{CH}_{2} \mathrm{~N}\right), 2.17\left(\mathrm{~s}, 6 \mathrm{H}, \mathrm{NCH}_{3}\right), 2.67-2.85\left(\mathrm{~m}, 4 \mathrm{H}, \mathrm{NCH}_{2}\right.$ $\left.\mathrm{CH}_{2} \mathrm{~N}\right), 2.88\left(\mathrm{~s}, 6 \mathrm{H}, \mathrm{NCH}_{3}\right), 3.32\left(\mathrm{~s}, 6 \mathrm{H}, \mathrm{OCH}_{3}\right), 3.39\left(\mathrm{~s}, 6 \mathrm{H}, \mathrm{OCH}_{3}\right)$, $3.77\left(\mathrm{~d},{ }^{2} \mathrm{~J}=14.0 \mathrm{~Hz}, 2 \mathrm{H}, \mathrm{NCH}_{2} \mathrm{C}-\mathrm{Ar}\right), 4.00\left(\mathrm{~d},{ }^{2} \mathrm{~J}=14.4 \mathrm{~Hz}, 2 \mathrm{H}\right.$, $\mathrm{NCH}_{2} \mathrm{C}-\mathrm{Ar}$ ), $4.22\left(\mathrm{~d},{ }^{2} \mathrm{~J}=14.0 \mathrm{~Hz}, 2 \mathrm{H}, \mathrm{NCH}_{2} \mathrm{C}-\mathrm{Ar}\right.$ ), 4.55 (dq, ${ }^{2} \mathrm{~J}=$ $\left.11.0 \mathrm{~Hz}, \quad 3 \mathrm{~J}=7.0 \mathrm{~Hz}, 2 \mathrm{H}, \quad \mathrm{OCH}_{2} \mathrm{CH}_{3}\right), 4.62\left(\mathrm{dq},{ }^{2} J=11.0 \mathrm{~Hz},{ }^{3} \mathrm{~J}=\right.$ $\left.7.0 \mathrm{~Hz}, 2 \mathrm{H}, \mathrm{OCH}_{2} \mathrm{CH}_{3}\right), 5.31\left(\mathrm{~d},{ }^{2} \mathrm{~J}=14.4 \mathrm{~Hz}, 2 \mathrm{H}, \mathrm{NCH}_{2} \mathrm{C}-\mathrm{Ar}\right.$ ), 6.17 
(d, ${ }^{3} J=7.8 \mathrm{~Hz}, 2 \mathrm{H}, \mathrm{H}-\mathrm{Ar}$ ), $6.24\left(\mathrm{~d},{ }^{3} J=7.8 \mathrm{~Hz}, 2 \mathrm{H}, \mathrm{H}-\mathrm{Ar}\right.$ ), 6.52 (d, $\left.{ }^{3} J=7.8 \mathrm{~Hz}, 2 \mathrm{H}, \mathrm{H}-\mathrm{Ar}\right), 6.73(\mathrm{~d}, 3 \mathrm{~J}=7.8 \mathrm{~Hz}, 2 \mathrm{H}, \mathrm{H}-\mathrm{Ar}), 7.10(\mathrm{dd}$, ${ }^{3} J_{1}={ }^{3} J_{2}=7.8 \mathrm{~Hz}, 2 \mathrm{H}, \mathrm{H}-\mathrm{Ar}$ ), $7.22 \mathrm{ppm}\left(\mathrm{dd},{ }^{3} J_{1}={ }^{3} J_{2}=7.8 \mathrm{~Hz}, 2 \mathrm{H}\right.$, $\mathrm{H}-\mathrm{Ar}) ;{ }^{13} \mathrm{C}$-NMR $\left(101 \mathrm{MHz}, \mathrm{C}_{6} \mathrm{D}_{6}\right): \delta=19.44\left(\mathrm{OCH}_{2} \mathrm{CH}_{3}\right), 47.88$ $\left(\mathrm{NCH}_{3}\right), 47.96\left(\mathrm{NCH}_{3}\right), 51.78\left(\mathrm{NCH}_{2} \mathrm{CH}_{2} \mathrm{~N}\right), 52.64\left(\mathrm{NCH}_{2} \mathrm{CH}_{2} \mathrm{~N}\right), 55.42$ $\left(\mathrm{OCH}_{3}\right), 55.50\left(\mathrm{OCH}_{3}\right), 56.37\left(\mathrm{NCH}_{2} \mathrm{C}-\mathrm{Ar}\right), 56.81\left(\mathrm{NCH}_{2} \mathrm{C}-\mathrm{Ar}\right), 72.40$ $\left(\mathrm{OCH}_{2} \mathrm{CH}_{3}\right), 100.86(\mathrm{C}-\mathrm{Ar}), 100.87(\mathrm{C}-\mathrm{Ar}), 111.34(\mathrm{C}-\mathrm{Ar}), 111.76$ (C-Ar), 113.58 (C-Ar), 114.22 (C-Ar), 128.31 (C-Ar), 128.87 (C-Ar), 159.11 (C-Ar), 159.14 (C-Ar), 164.11 (C-Ar), 164.18 ppm (C-Ar); UV/Vis $\left(\mathrm{CHCl}_{3}\right): \lambda_{\max }(\varepsilon)=316\left(23,504 \mathrm{M}^{-1} \mathrm{~cm}^{-1}\right)$; IR (ATR): $v=3013.47(w), 2855.37(w), 1589.70(\mathrm{~m}), 1573.66(\mathrm{~m})$, 1462.85 (s), 1376.22 (w), 1301.44 (m), 1242.82 (s), 1088.65 (s), $1145.00(\mathrm{w}), 1056.59(\mathrm{~s}), 1007.67(\mathrm{~m}), 964.41(\mathrm{~m}), 903.85(\mathrm{~m})$, 752.53 (s), 718.35 (s), $695.70 \mathrm{~cm}^{-1}$ (s); m.p. $240.0-242.0^{\circ} \mathrm{C}$ (EtOH/ toluene, yellow platelets); elemental analysis calcd (\%) for $\mathrm{C}_{44} \mathrm{H}_{62} \mathrm{~N}_{4} \mathrm{O}_{11}$ : C 57.52, H 6.80, N 6.10; found: C 57.36, H 6.71, N 6.05.

\subsection{X-ray crystallographic studies}

Data collection was performed with a STOE IPDS-II diffractometer equipped with a graphite monochromated radiation source $(\lambda=0.71073 \AA)$, an image plate detection system and an Oxford Cryostream 700 with nitrogen as coolant gas. The selection, integration, and averaging procedure of the measured reflex intensities, the determination of the unit cell by a least-squares fit of the $2 \theta$ values, data reduction, LP correction, and the space group determination were performed using the X-Area software package delivered with the diffractometer [25]. A semi-empirical absorption correction method was used after indexing of the crystal faces. Structures were solved by direct methods either with SHELXS-97 [26] ([TiL $\left.\left.{ }^{2}(\mathrm{OEt})_{2}\right]\right)$ or SIR-97 [27] ([ $\left.\left.\mathrm{L}^{1}(\mathrm{OEt}) \mathrm{Ti}-\mathrm{O}-\mathrm{Ti}(\mathrm{OEt}) \mathrm{L}^{1}\right]\right)$ and refined by standard Fourier techniques against $F^{2}$ with a full-matrix leastsquares algorithm using SHELXL-97 [26] and the WinGX (1.80.05) [28] software package. All non-hydrogen atoms were refined anisotropically. Hydrogen atoms were placed in calculated positions and refined with a riding model. Graphical representations were prepared with ORTEP-III [29]. The program PLATON [30] was used to check the results of the X-ray crystal structure determination.

\subsubsection{Crystal data for $\left[T^{2} L^{2}(O E t)_{2}\right]$}

$\mathrm{C}_{24} \mathrm{H}_{36} \mathrm{~N}_{2} \mathrm{O}_{6} \mathrm{Ti}, M=496.45$, monoclinic, $P 21 / c, a=12.4419(11)$, $b=12.6233(7), c=19.0955(17) \AA, \beta=125.596(6)^{\circ}, V=2438.7(3) \AA^{3}$, $T=100(2) \mathrm{K}, \mathrm{Z}=4, \rho_{\text {calcd }}=1.352 \mathrm{~g} \mathrm{~cm}^{-3}, \mu\left(\mathrm{Mo}_{\mathrm{K} \alpha}\right)=0.392 \mathrm{~mm}^{-1}$, 31,005 reflections collected, 4806 unique $\left(R_{\text {int }}=0.0870\right), R_{1}$ for
$[I>2 \sigma(I)]=0.0548, w R_{2}$ for all $=0.1123$. Single crystals of $\left[\mathrm{TiL}^{2}(\mathrm{OEt})_{2}\right]$ were grown from solutions in ethanol by slow evaporation at $6{ }^{\circ} \mathrm{C}$.

\subsubsection{Crystal data for $\left[L^{1}(\mathrm{OEt}) T i-O-T i(O E t) L^{1}\right]$}

$\mathrm{C}_{44} \mathrm{H}_{62} \mathrm{~N}_{4} \mathrm{O}_{11} \mathrm{Ti}, M=918.72$, monoclinic, $C 2 / c, a=44.5019(18)$, $b=11.0477(5), c=19.3169(9) \AA, \beta=113.729(3)^{\circ}, V=8694.2(6) \AA^{3}$, $T=100(2) \mathrm{K}, \mathrm{Z}=8, \rho_{\text {calcd. }}=1.404 \mathrm{~g} \mathrm{~cm}^{-3}, \mu\left(\mathrm{Mo}_{\mathrm{K \alpha}}\right)=0.433 \mathrm{~mm}^{-1}$, 63,223 reflections collected, 9270 unique $\left(\mathrm{R}_{\mathrm{int}}=0.0756\right), R_{1}$ for $[I>2 \sigma(I)]=0.0579, w R_{2}$ for all $=0.1442$. Single crystals of $\left[\mathrm{L}^{1}(\mathrm{OEt}) \mathrm{Ti}-\right.$ $\mathrm{O}$-Ti(OEt) $\left.\mathrm{L}^{1}\right]$ were grown from a saturated solution of the complex in ethanol at $-20^{\circ} \mathrm{C}$.

\subsection{Time resolved hydrolysis studies using ${ }^{\prime} H$-NMR-spectroscopy}

Hydrolysis experiments followed by ${ }^{1} \mathrm{H}-\mathrm{NMR}$ spectroscopy were conducted in a mixture of $95 \%\left[\mathrm{D}_{8}\right] \mathrm{THF}$ and $4.8 \% \mathrm{D}_{2} \mathrm{O}$ and $0.2 \%$ DMSO at $37^{\circ} \mathrm{C}$. Spectra were recorded at regular intervals. Data analysis was achieved by monitoring the decrease of at least two well-isolated signals of the titanium bound salan backbone and the increase of the evolving signals of unbound ethoxide over time. Resulting integrals were normalized against the internal standard (DMSO) and plotted against elapsed time. Control measurements without DMSO showed no significant alteration of hydrolysis rate and products formed. Plotted data for the hydrolysis of mono- and binuclear complexes $\left[\mathrm{TiL}^{1}(\mathrm{OEt})_{2}\right],\left[\mathrm{TiL}^{3}(\mathrm{OEt})_{2}\right], \quad\left[\mathrm{L}^{1}(\mathrm{OEt}) \mathrm{Ti}-\mathrm{O}-\mathrm{Ti}\right.$ $\left.(\mathrm{OEt}) \mathrm{L}^{1}\right]$ and $\left[\mathrm{L}^{3}(\mathrm{OEt}) \mathrm{Ti}-\mathrm{O}-\mathrm{Ti}(\mathrm{OEt}) \mathrm{L}^{3}\right]$ can be found as figures $\mathrm{S} 1$ and S2 in the electronic supplements to this manuscript. Table 4 summarizes the calculated $\mathrm{t}_{1 / 2}$-values of all complexes.

\subsection{Cytotoxicity assay}

Cytotoxicity was estimated in cells of human HeLa S3 cervix carcinoma and Hep G2 liver carcinoma cells obtained from European Collection of Cell Cultures (ECACC) using an AlamarBlue based assay $[31,32]$. AlamarBlue was purchased from BioSource Europe.

Cells were cultivated at $37^{\circ} \mathrm{C}$ in humidified $5 \% \mathrm{CO}_{2}$ atmosphere using Dulbecco's DMEM-medium (Invitrogen) containing $10 \%$ fetal calf serum, $1 \%$ penicillin and $1 \%$ streptomycin. Cells were split every three days. Both cell lines were tested for mycoplasma infections using a mycoplasma detection kit (Roche Applied Science).

AlamarBlue, the dark blue colored sodium salt of resazurin (7hydroxy-3H-phenoxazin-3-one-10-oxide) was used to measure growth and viability of cells which are capable of reducing it to the fluorescent, pink colored resorufin (7-hydroxy-3H-phenoxazin-3one). Cells were seeded in 96-well plates ( 4000 HeLa S3 cells/well

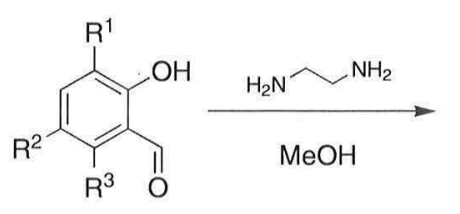<smiles>[R]c1cc([R])c(O)c(/C=N\CC/N=C/c2c([R])c([R])cc([R])c2O)c1[R]</smiles>

$\mathrm{SB}^{1-3}$<smiles>[R7]c1cc([R])c(O)c(CNCCNCc2c([R])cc([R7])c(O)c2[R])c1</smiles><smiles>COC(C)=O</smiles><smiles>[R]c1cc([R])c(O)c(CN(C)CCN(C)Cc2c(O)c([R])cc([R])c2O)c1[R]</smiles>

$\mathrm{H}_{4} \mathrm{~L}^{1-3}$
$\mathrm{H}_{2} \mathrm{~L}^{1-3}$ 
<smiles>[R7]c1cc([R])c(O)c(CN(C)CCN(C)Cc2c([R])c([R7])cc([R])c2O)c1</smiles>

$\mathrm{H}_{2} \mathrm{~L}^{1-3}$

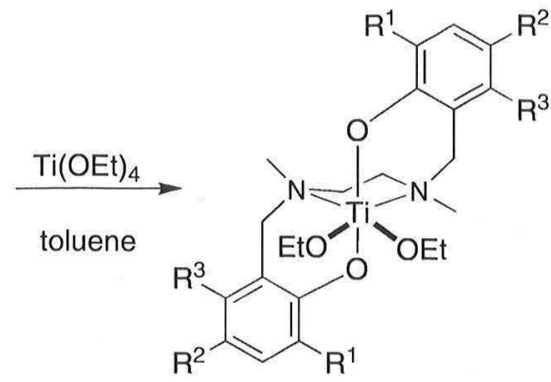

$\left[T_{i L}{ }^{1}(\mathrm{OEt})_{2}\right]: \mathrm{R}^{1}=\mathrm{OMe}, \mathrm{R}^{2}=\mathrm{R}^{3}=\mathrm{H}$

$\left[\mathrm{TiL}^{2}(\mathrm{OEt})_{2}\right]: \mathrm{R}^{1}=\mathrm{H}, \mathrm{R}^{2}=\mathrm{OMe}, \mathrm{R}^{3}=\mathrm{H}$

$\left[\mathrm{TiL}^{3}(\mathrm{OEt})_{2}\right]: \mathrm{R}^{1}=\mathrm{R}^{2}=\mathrm{H}, \mathrm{R}^{3}=\mathrm{OMe}$

Scheme 2. Synthesis of $\left[\mathrm{TiL}^{1-3}(\mathrm{OEt})_{2}\right]$.

or 8000 Hep G2 cells/well) and allowed to attach and grow for $24 \mathrm{~h}$. Complexes to be tested were dissolved in a suitable amount of DMSO. Different concentrations were prepared by serial dilution with medium to give final concentrations with a maximum DMSO content of $1 \%$. The cells were then incubated for $48 \mathrm{~h}$ with $100 \mu \mathrm{l}$ each of above dilution series. AlamarBlue $(10 \mu \mathrm{l})$ was added and the cells were incubated for another hour. After excitation at $530 \mathrm{~nm}$, fluorescence at $590 \mathrm{~nm}$ was measured using a Synergy 2 HT Fluorescence Microplate Reader (BioTek). Cell viability is expressed as a percentage with respect to a control containing only pure medium and 1\% DMSO incubated under identical conditions. All experiments were repeated for a minimum of three times with each experiment done in four replicates. The resulting curves were fitted using Sigma plot 10.0 [33]. Viability charts (Figures S3-S7) of mono- and dinuclear complexes [ $\left.\mathrm{TiL}^{1}(\mathrm{OEt})_{2}\right],\left[\mathrm{TiL}^{2}(\mathrm{OEt})_{2}\right],\left[\mathrm{TiL}^{3}(\mathrm{OEt})_{2}\right],\left[\mathrm{L}^{1}(\mathrm{OEt}) \mathrm{Ti}-\mathrm{O}-\mathrm{Ti}\right.$

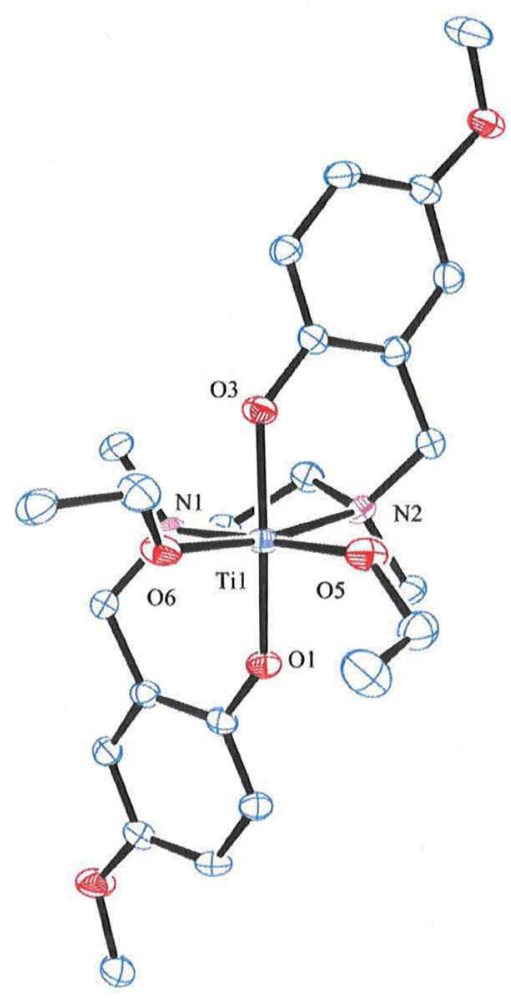

Fig. 1. ORTEP diagram of the molecular structures of $\left[\mathrm{TiL}^{2}(\mathrm{OEt})_{2}\right]$. Displacement ellip soids are drawn at the $50 \%$ probability level. Hydrogen atoms are omitted for clarity.
$\left.(\mathrm{OEt}) \mathrm{L}^{1}\right]$, and $\left[\mathrm{L}^{3}(\mathrm{OEt}) \mathrm{Ti}-\mathrm{O}-\mathrm{Ti}(\mathrm{OEt}) \mathrm{L}^{3}\right]$ after $48 \mathrm{~h}$ of incubation in HeLa S3 and Hep G2 cells respectively can be found in the electronic supplements to this manuscript.

\section{Results and discussion}

The synthesis of the methoxy salans $\mathrm{H}_{2} \mathrm{~L}^{1-3}$ was achieved by a sequence of two subsequent reductive aminations (Scheme 1).

Starting from ethylenediamine and the respective methoxy salicylaldehyde gave ligand precursors $\mathrm{H}_{4} \mathrm{~L}^{1-3}$ in good yields [34]. Reductive methylation of $\mathrm{H}_{4} \mathrm{~L}^{1,2}$ proceeded smoothly to yield $\mathrm{H}_{2} \mathrm{~L}^{1,2}$ whereas the formation of a red polymeric byproduct decreased the yield of $\mathrm{H}_{2} \mathrm{~L}^{3}$ because of heavy cross-linking via both activated 0 and $p$-positions. Metalation of the three salans $\mathrm{H}_{2} \mathrm{~L}^{1-3}$ with titanium (IV) ethoxide in toluene at room temperature led to the formation of $\left[\mathrm{TiL}^{1-3}(\mathrm{OEt})_{2}\right]$ as single (racemic) isomers in nearly quantitative yield (Scheme 2) [35].

${ }^{1} \mathrm{H}$-NMR spectra of $\left[\mathrm{TiL}^{1-3}(\mathrm{OEt})_{2}\right]$ showed the familiar $\mathrm{AB}$ pattern of the benzylic protons consistent with $C_{2}$ symmetry and a fac-fac wrapping of the salan around the titanium center. Single crystals of $\left[\mathrm{TiL}^{2}(\mathrm{OEt})_{2}\right]$ suitable for X-ray crystal structure determination were grown from ethanol.

$\left[\mathrm{TiL}^{2}(\mathrm{OEt})_{2}\right]$ crystallizes in the monoclinic system in the centrosymmetric space group $P 2_{1} / c$, with one molecule in the asymmetric unit and no additional solvent. The crystal structure confirmed the $C_{2}$ symmetry with the labile ethoxy ligands bound in a cis fashion at the equatorial plane and the phenolates occupying the bis-trans-axial positions of the slightly distorted octahedral complex (Fig. 1). With 1.82-1.83 $\AA$ for the titanium-alkoxide and $1.90 \AA$ for the titanium-phenolate distances, bond-lengths around the titanium center are well comparable with the methyl substituted members of this class of complexes [14]. The electron richness usually attributed to methoxy-substituted

Table 1

$\mathrm{IC}_{50}[\mu \mathrm{M}]$ values in Hela $\mathrm{S} 3$ and Hep $\mathrm{G} 2$ cells estimated by AlamarBlue assay after $48 \mathrm{~h}$ incubation with [TiL ${ }^{1-3}(\mathrm{OEt})_{2}$ ] or ligands $\mathrm{H}_{2} \mathrm{~L}^{1-3}$ respectively. All $\mathrm{IC}_{50}$ values given in $\mathrm{IM}$ are means from at least three independent experiments each done in four replicates.

\begin{tabular}{lll}
\hline Ligand/complex & $\mathrm{IC}_{50}$ in HeLa S3 & $\mathrm{IC}_{50}$ in Hep G2 \\
\hline$\left[\mathrm{TiL}^{1}(\mathrm{OEt})_{2}\right]$ & $6.2 \pm 0.5$ & $13.0 \pm 1.7$ \\
{$\left[\mathrm{TiL}^{2}(\mathrm{OEt})_{2}\right]$} & $4.0 \pm 0.6$ & $5.4 \pm 0.8$ \\
{$\left[\mathrm{TiL}^{3}(\mathrm{OEt})_{2}\right]$} & $6.2 \pm 0.4$ & $7.6 \pm 3.4$ \\
$\mathrm{H}_{2} \mathrm{~L}^{1}$ & $46.9 \pm 15.6$ & $48.6 \pm 13.1$ \\
$\mathrm{H}_{2} \mathrm{~L}^{2}$ & $>100$ & $>100$ \\
$\mathrm{H}_{2} \mathrm{~L}^{3}$ & $37.6 \pm 8.4$ & $69.5 \pm 11.2$ \\
Cisplatin $^{a}$ & $1.2 \pm 0.4$ & $3.0 \pm 1.3$ \\
\hline
\end{tabular}

\footnotetext{
${ }^{a}$ Cisplatin served as the reference compound in all assays.
} 


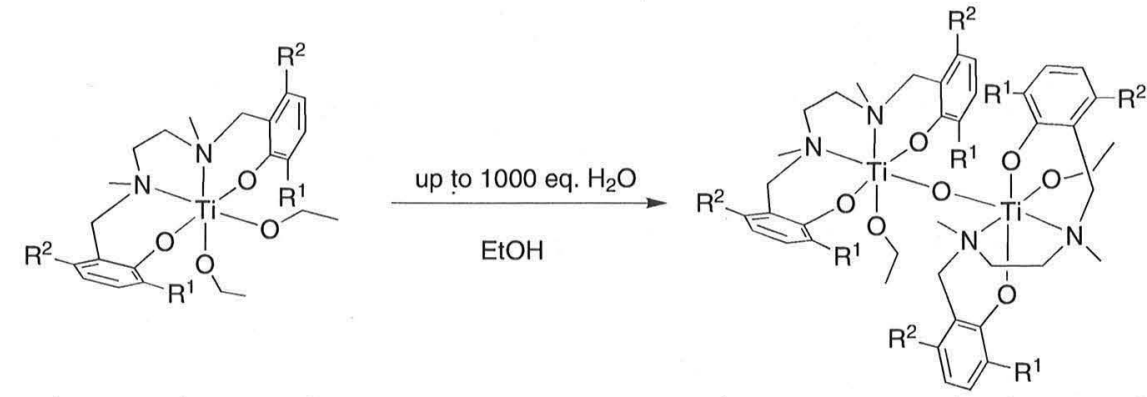

$\left[\mathrm{TiL}^{1}(\mathrm{OEt})_{2}\right]: \mathrm{R}^{1}=\mathrm{OMe}, \mathrm{R}^{2}=\mathrm{H}$

$\left[L^{1}\left(\right.\right.$ OEt)Ti-O-Ti(OEt) $\left.L^{1}\right]: R^{1}=O M e, R^{2}=H, 80 \%$ $\left[\mathrm{TiL}^{3}(\mathrm{OEt})_{2}\right]: \mathrm{R}^{1}=\mathrm{H}, \mathrm{R}^{2}=\mathrm{OMe}$

$\left[\mathrm{L}^{3}\right.$ (OEt)Ti-O-Ti(OEt) $\left.L^{3}\right]: R^{1}=H, R^{2}=O M e, 85 \%$

Scheme 3. Partial hydrolysis resulting in the exclusive formation of dinuclear $\left[\mathrm{L}^{1,3}(\mathrm{OEt}) \mathrm{Ti}-\mathrm{O}-\mathrm{Ti}(\mathrm{OEt}) \mathrm{L}^{1,3}\right]$.

arenes is not apparent in the bonding parameters of the complexes $\left[\mathrm{TiL}^{1-3}(\mathrm{OEt})_{2}\right]$.

To estimate the cytotoxicity of these donor substituted complexes, their efficacy was screened in two human tumor cell lines (Hela S3 and Hep G2) using the AlamarBlue assay [31, 32]. Cisplatin served as the reference compound in all assays. To verify that the observed cytotoxicity does not originate from the free ligands those were also tested. Data are summarized in Table 1.

All three complexes showed cytotoxicity in a low $\mu$-molar range and therefore belong to the group of highly bioactive titanium complexes, whereas the ligands $\mathrm{H}_{2} \mathrm{~L}^{1-3}$ exhibited only limited toxicity.

The formation of dinuclear complexes $\left[\mathrm{L}^{1,3}(\mathrm{OEt}) \mathrm{Ti}-\mathrm{O}-\mathrm{Ti}(\mathrm{OEt})\right.$ $\left.\mathrm{L}^{1,3}\right]$ was achieved by suspending $\left[\mathrm{TiL}^{1.3}(\mathrm{OEt})_{2}\right]$ in an ethanol/water mixture $(95: 5)$ at $60^{\circ} \mathrm{C}$. To this additional solvent was slowly added until all starting material had dissolved. Intriguingly, ${ }^{1} \mathrm{H}-\mathrm{NMR}$ spectra recorded from the crude reaction mixtures revealed the very rapid formation of an apparently highly symmetric single new compound in both cases. The reaction proved surprisingly tolerant against the amount of water being added, similar spectra were recorded when the amount of water varied between 10 and 1000 equivalents, the

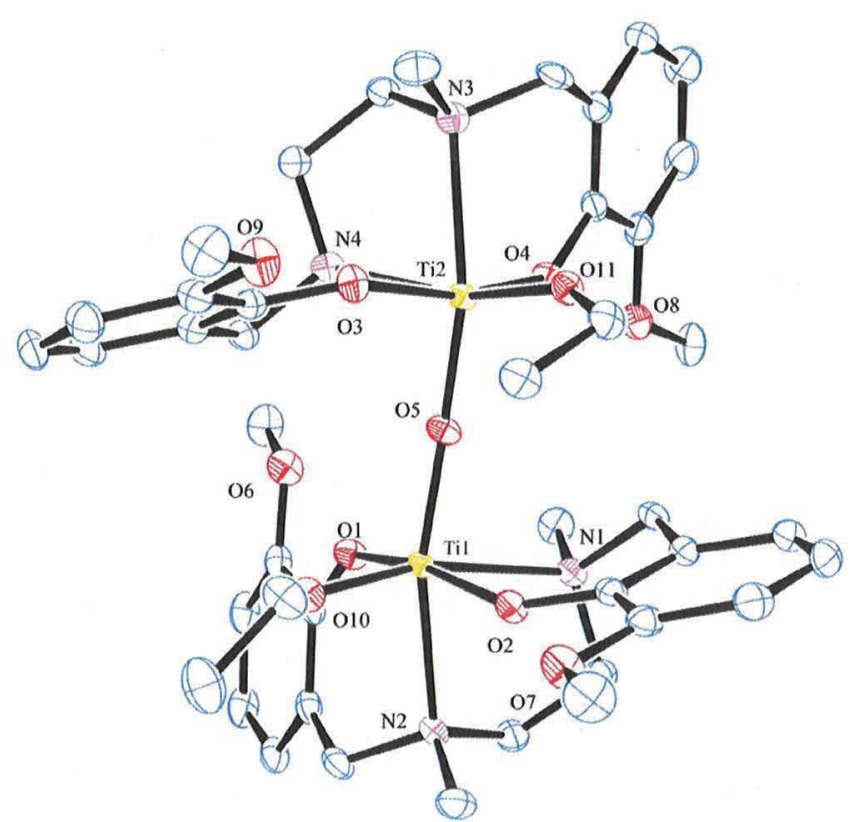

Fig. 2. ORTEP diagram of the molecular structures of $\left[\mathrm{L}^{1}(\mathrm{OEt}) \mathrm{Ti}-\mathrm{O}-\mathrm{Ti}(\mathrm{OEt}) \mathrm{L}^{1}\right]$ with the two remaining labile ligands $(011,010)$ pointing towards the front. Displacement ellipsoids are drawn at the $50 \%$ probability level. Hydrogen atoms are omitted for clarity. new compounds were isolated as microcrystalline material in $\geq 80 \%$ yield. Signals from the salan ligands appeared doubled in the ${ }^{1} \mathrm{H}$ NMR but no liberation of either free salans $\mathrm{H}_{2} \mathrm{~L}^{1}$ or $\mathrm{H}_{2} \mathrm{~L}^{3}$ was observed. Most strikingly, the ratio of labile to salan ligand had changed. From the integral ratio, it seemed that each new compound had lost one of its labile ethoxy groups. Hence, it was anticipated that a dinuclear species similar to the complexes described by Nielson and Waters [17] with one bridging oxo-ligand in place of the former labile ligand had formed by partial hydrolysis, thus, giving reason for the symmetry reflected by the NMR spectra (Scheme 3).

Attempts to grow single crystals suitable for X-ray crystal structure determination proved difficult because of both compounds' pronounced tendency to form very thin platelets. Finally, after keeping a solution of $\left[\mathrm{L}^{1}(\mathrm{OEt}) \mathrm{Ti}-\mathrm{O}-\mathrm{Ti}(\mathrm{OEt}) \mathrm{L}^{1}\right]$ for several weeks at freezer temperature, suitable crystals began to separate from the solution. The structure solved showed nearly perfect $C_{2}$-symmetry around the $\mu_{2}$-oxo bridge (05, Fig. 2 ) as center of symmetry.

Both hemispheres of the dinuclear complex still feature the lightly distorted octahedral geometry known from the mononuclear salan complexes. That is, the phenolates (01-Ti1-02 and 04-Ti2-03) are oriented in a bis-trans-axial fashion while the amino and oxo ligands are bound pair-wise in cis-fashion at the equatorial plane. Bond length and angles show very little variation when comparing the mononuclear $\left[\mathrm{TiL}^{2}(\mathrm{OEt})_{2}\right]$ with the dinuclear $\left[\mathrm{L}^{1}(\mathrm{OEt}) \mathrm{Ti}-\mathrm{O}-\mathrm{Ti}\right.$ $(\mathrm{OEt}) \mathrm{L}^{1}$ ] (Selected bond length and angles of both new complexes are tabulated in Tables 2 and 3 ).

The half-life of mononuclear and dinuclear complexes under hydrolytic conditions at $37^{\circ} \mathrm{C}$ was estimated routinely by NMR spectroscopy in a mixture consisting of $95 \%\left[\mathrm{D}_{8}\right] \mathrm{THF}, 4.8 \% \mathrm{D}_{2} \mathrm{O}$ and $0.2 \%$ DMSO as internal standard [14]. All methoxy salan complexes studied showed a remarkable sensitivity towards hydrolysis. Compared with methyl-substituted salan complexes with half-lives of several hours or halogen-substituted ones with half-lives of more than $120 \mathrm{~h} \mathrm{[14],}$ $\left[\mathrm{TiL}^{1,2}(\mathrm{OEt})_{2}\right]$ and the respective dinuclear complexes $\left[\mathrm{L}^{1,3}(\mathrm{OEt})\right.$

Table 2

Selected bond lengths $[\AA \AA]$ and angles $\left[^{\circ}\right]$ for $\left[\operatorname{TiL}^{2}(\mathrm{OEt})_{2}\right]$.

\begin{tabular}{lccr}
\hline$\left[\mathrm{TiL}^{2}(\mathrm{OEt})_{2}\right]$ & & & \\
\hline $\mathrm{Ti}(1)-\mathrm{O}(5)$ & $1.817(2)$ & $\mathrm{O}(1)-\mathrm{Ti}(1)-\mathrm{O}(3)$ & $167.06(9)$ \\
$\mathrm{Ti}(1)-\mathrm{O}(6)$ & $1.834(2)$ & $\mathrm{O}(5)-\mathrm{Ti}(1)-\mathrm{N}(2)$ & $88.03(9)$ \\
$\mathrm{Ti}(1)-\mathrm{O}(1)$ & $1.8988(18)$ & $\mathrm{O}(6)-\mathrm{Ti}(1)-\mathrm{N}(2)$ & $165.43(9)$ \\
$\mathrm{Ti}(1)-\mathrm{O}(3)$ & $1.9014(19)$ & $\mathrm{O}(1)-\mathrm{Ti}(1)-\mathrm{N}(2)$ & $89.39(8)$ \\
$\mathrm{Ti}(1)-\mathrm{N}(2)$ & $2.314(2)$ & $\mathrm{O}(3)-\mathrm{Ti}(1)-\mathrm{N}(2)$ & $81.39(8)$ \\
$\mathrm{Ti}(1)-\mathrm{N}(1)$ & $2.322(2)$ & $\mathrm{O}(5)-\mathrm{Ti}(1)-\mathrm{N}(1)$ & $163.28(9)$ \\
$\mathrm{O}(5)-\mathrm{Ti}(1)-\mathrm{O}(6)$ & $105.40(10)$ & $\mathrm{O}(6)-\mathrm{Ti}(1)-\mathrm{N}(1)$ & $90.97(9)$ \\
$\mathrm{O}(5)-\mathrm{Ti}(1)-\mathrm{O}(1)$ & $92.75(9)$ & $\mathrm{O}(1)-\mathrm{Ti}(1)-\mathrm{N}(1)$ & $82.13(8)$ \\
$\mathrm{O}(6)-\mathrm{Ti}(1)-\mathrm{O}(1)$ & $95.47(9)$ & $\mathrm{O}(3)-\mathrm{Ti}(1)-\mathrm{N}(1)$ & $86.83(8)$ \\
$\mathrm{O}(5)-\mathrm{Ti}(1)-\mathrm{O}(3)$ & $95.97(9)$ & $\mathrm{N}(2)-\mathrm{Ti}(1)-\mathrm{N}(1)$ & $76.07(8)$ \\
$\mathrm{O}(6)-\mathrm{Ti}(1)-\mathrm{O}(3)$ & $91.42(8)$ & & \\
\hline
\end{tabular}


Table 3

Selected bond lengths $[\AA \AA]$ and angles $\left[^{\circ}\right]$ for $\left[\mathrm{L}^{1}(\mathrm{OEt}) \mathrm{Ti}-\mathrm{O}-\mathrm{Ti}(\mathrm{OEt}) \mathrm{L}^{1}\right]$.

\begin{tabular}{lrlr}
\hline$\left[\mathrm{L}^{1}(\mathrm{OEt}) \mathrm{Ti}-\mathrm{O}-\mathrm{Ti}(\mathrm{OEt}) \mathrm{L}^{1}\right]$ & & \\
\hline $\mathrm{N}(1)-\mathrm{Ti}(1)$ & $2.342(3)$ & $\mathrm{O}(1)-\mathrm{Ti}(1)-\mathrm{N}(1)$ & $91.03(10)$ \\
$\mathrm{N}(2)-\mathrm{Ti}(1)$ & $2.354(3)$ & $\mathrm{O}(10)-\mathrm{Ti}(1)-\mathrm{N}(2)$ & $91.92(11)$ \\
$\mathrm{N}(3)-\mathrm{Ti}(2)$ & $2.346(3)$ & $\mathrm{O}(5)-\mathrm{Ti}(1)-\mathrm{N}(2)$ & $161.38(11)$ \\
$\mathrm{N}(4)-\mathrm{Ti}(2)$ & $2.343(3)$ & $\mathrm{O}(2)-\mathrm{Ti}(1)-\mathrm{N}(2)$ & $85.29(10)$ \\
$\mathrm{O}(1)-\mathrm{Ti}(1)$ & $1.922(2)$ & $\mathrm{O}(1)-\mathrm{Ti}(1)-\mathrm{N}(2)$ & $81.43(10)$ \\
$\mathrm{O}(2)-\mathrm{Ti}(1)$ & $1.898(2)$ & $\mathrm{N}(1)-\mathrm{Ti}(1)-\mathrm{N}(2)$ & $75.24(10)$ \\
$\mathrm{O}(3)-\mathrm{Ti}(2)$ & $1.900(2)$ & $\mathrm{O}(11)-\mathrm{Ti}(2)-\mathrm{O}(5)$ & $106.74(11)$ \\
$\mathrm{O}(4)-\mathrm{Ti}(2)$ & $1.952(2)$ & $\mathrm{O}(11)-\mathrm{Ti}(2)-\mathrm{O}(3)$ & $93.90(11)$ \\
$\mathrm{O}(5)-\mathrm{Ti}(2)$ & $1.815(2)$ & $\mathrm{O}(5)-\mathrm{Ti}(2)-\mathrm{O}(3)$ & $96.73(11)$ \\
$\mathrm{O}(5)-\mathrm{Ti}(1)$ & $1.822(2)$ & $\mathrm{O}(11)-\mathrm{Ti}(2)-\mathrm{O}(4)$ & $95.09(11)$ \\
$\mathrm{O}(10)-\mathrm{Ti}(1)$ & $1.816(2)$ & $\mathrm{O}(5)-\mathrm{Ti}(2)-\mathrm{O}(4)$ & $93.86(10)$ \\
$\mathrm{O}(11)-\mathrm{Ti}(2)$ & $1.812(2)$ & $\mathrm{O}(3)-\mathrm{Ti}(2)-\mathrm{O}(4)$ & $163.53(11)$ \\
$\mathrm{Ti}(2)-\mathrm{O}(5)-\mathrm{Ti}(1)$ & $169.15(14)$ & $\mathrm{O}(11)-\mathrm{Ti}(2)-\mathrm{N}(4)$ & $165.34(10)$ \\
$\mathrm{O}(10)-\mathrm{Ti}(1)-\mathrm{O}(5)$ & $106.58(11)$ & $\mathrm{O}(5)-\mathrm{Ti}(2)-\mathrm{N}(4)$ & $87.18(10)$ \\
$\mathrm{O}(10)-\mathrm{Ti}(1)-\mathrm{O}(2)$ & $90.94(11)$ & $\mathrm{O}(3)-\mathrm{Ti}(2)-\mathrm{N}(4)$ & $79.60(10)$ \\
$\mathrm{O}(5)-\mathrm{Ti}(1)-\mathrm{O}(2)$ & $96.29(10)$ & $\mathrm{O}(4)-\mathrm{Ti}(2)-\mathrm{N}(4)$ & $88.39(10)$ \\
$\mathrm{O}(10)-\mathrm{Ti}(1)-\mathrm{O}(1)$ & $94.98(11)$ & $\mathrm{O}(11)-\mathrm{Ti}(2)-\mathrm{N}(3)$ & $90.84(11)$ \\
$\mathrm{O}(5)-\mathrm{Ti}(1)-\mathrm{O}(1)$ & $94.57(10)$ & $\mathrm{O}(5)-\mathrm{Ti}(2)-\mathrm{N}(3)$ & $162.19(10)$ \\
$\mathrm{O}(2)-\mathrm{Ti}(1)-\mathrm{O}(1)$ & $165.62(11)$ & $\mathrm{O}(3)-\mathrm{Ti}(2)-\mathrm{N}(3)$ & $84.63(11)$ \\
$\mathrm{O}(10)-\mathrm{Ti}(1)-\mathrm{N}(1)$ & $164.87(11)$ & $\mathrm{O}(4)-\mathrm{Ti}(2)-\mathrm{N}(3)$ & $81.47(10)$ \\
$\mathrm{O}(5)-\mathrm{Ti}(1)-\mathrm{N}(1)$ & $86.71(10)$ & $\mathrm{N}(4)-\mathrm{Ti}(2)-\mathrm{N}(3)$ & $75.56(10)$ \\
$\mathrm{O}(2)-\mathrm{Ti}(1)-\mathrm{N}(1)$ & $80.22(10)$ & & \\
\hline
\end{tabular}

$\mathrm{Ti}-\mathrm{O}-\mathrm{Ti}(\mathrm{OEt}) \mathrm{L}^{1,3}$ ] showed a drastic accelerated speed of hydrolysis and the formation of higher aggregates with no liberation of salan. Both mononuclear complexes show a $t_{1 / 2}$ of less than $1 \mathrm{~h}$. Surprisingly, the dinuclear complexes hydrolyze with comparable speed, with $\left[\mathrm{L}^{3}(\mathrm{OEt}) \mathrm{Ti}-\mathrm{O}-\mathrm{Ti}(\mathrm{OEt}) \mathrm{L}^{3}\right]$ being slightly more stable than $\left[\mathrm{L}^{1}(\mathrm{OEt})\right.$ Ti-O-Ti(OEt) $\mathrm{L}^{1}$ ]. Table 4 summarizes the results.

Both dinuclear complexes were screened for their bioactivity in the AlamarBlue assay as the mononuclear compounds had been before. Knowing from former studies [14] that cytotoxicity is extremely diminished when complex size is increased, we were quite impressed that $\left[\mathrm{L}^{3}(\mathrm{OEt}) \mathrm{Ti}-\mathrm{O}-\mathrm{Ti}(\mathrm{OEt}) \mathrm{L}^{3}\right]$ showed only a threefold decreased activity and $\left[\mathrm{L}^{1}(\mathrm{OEt}) \mathrm{Ti}-\mathrm{O}-\mathrm{Ti}(\mathrm{OEt}) \mathrm{L}^{1}\right]$ had an even twofold increased activity compared to their respective mononuclear starting compounds (Table 5). The bioactivity of both dinuclear complexes corroborates our hypothesis that the presence of labile ligands is a prerequisite for cytotoxicity.

\section{Conclusions}

We recently showed that by increasing the sterical demand of complexes their cytotoxicity decreased dramatically [14]. Interestingly, the herein described dinuclear complexes $\left[\mathrm{L}^{1,3}(\mathrm{OEt}) \mathrm{Ti}-\mathrm{O}-\mathrm{Ti}(\mathrm{OEt})\right.$ $\left.\mathrm{L}^{1,3}\right]$ formed by partially hydrolysis of $\left[\mathrm{TiL}^{1,3}(\mathrm{OEt})_{2}\right]$ show strong cytotoxicity even so they are quite bulky. In contrast to known cyclic trinuclear titanium(IV) species recently described as being nontoxic $[15,16]$, the dinuclear $\left[\mathrm{L}^{1,3}(\mathrm{OEt}) \mathrm{Ti}-\mathrm{O}-\mathrm{Ti}(\mathrm{OEt}) \mathrm{L}^{1,3}\right]$ still feature replaceable ligands, thus potentially permitting the coordinative interaction with biomolecules. This is in contrast to mononuclear complexes which feature flat aromatic moieties and therefore might allow DNA intercalation [36], X-ray structure determination showed that $\left[\mathrm{L}^{1}(\mathrm{OEt}) \mathrm{Ti}-\mathrm{O}-\mathrm{Ti}(\mathrm{OEt}) \mathrm{L}^{1}\right]$ adopts an almost spherical shape. The pronounced toxicity of the dinuclear complexes thus makes a proposed involvement of DNA intercalation in the biological activity

Table 4

Half-life of complexes $\left[\mathrm{TiL}^{1,3}(\mathrm{OEt})_{2}\right]$ and $\left[\mathrm{L}^{1,3}(\mathrm{OEt}) \mathrm{Ti}-\mathrm{O}-\mathrm{Ti}(\mathrm{OEt}) \mathrm{L}^{1,3}\right]$ under hydrolytic conditions determined by time resolved NMR at $37^{\circ} \mathrm{C}$.

\begin{tabular}{llll}
\hline Complex & $\mathrm{t}_{1 / 2}[\mathrm{~min}]$ & Complex & $\mathrm{t}_{1 / 2}[\mathrm{~min}]$ \\
\hline$\left[\mathrm{TiL}^{1}(\mathrm{OEt})_{2}\right]$ & 50 & {$\left[\mathrm{~L}^{1}(\mathrm{OEt}) \mathrm{Ti}-\mathrm{O}-\mathrm{Ti}(\mathrm{OEt}) \mathrm{L}^{1}\right]$} & 50 \\
{$\left[\mathrm{TiL}^{2}(\mathrm{OEt})_{2}\right]$} & 60 & {$\left[\mathrm{~L}^{3}(\mathrm{OEt}) \mathrm{Ti}-\mathrm{O}-\mathrm{Ti}(\mathrm{OEt}) \mathrm{L}^{3}\right]$} & 130 \\
\hline
\end{tabular}

Table 5

$\mathrm{IC}_{\text {so }}[\mu \mathrm{M}]$ values in Hela S3 and Hep G2 cells after 48 h incubation with complexes [ $\mathrm{L}^{1,3}$ $(\mathrm{OEt}) \mathrm{Ti}-\mathrm{O}-\mathrm{Ti}(\mathrm{OEt}) \mathrm{L}^{1,3}$ ] estimated by AlamarBlue assay. All $\mathrm{IC}_{50}$ values given in $\mu \mathrm{M}$ are means from at least three independent experiments each done in four replicates.

\begin{tabular}{lcc}
\hline Complex & $\mathrm{IC}_{50}$ in HeLa S3 & $\mathrm{IC}_{50}$ in Hep G2 \\
\hline$\left[\mathrm{L}^{1}(\mathrm{OEt}) \mathrm{Ti}-\mathrm{O}-\mathrm{Ti}(\mathrm{OEt}) \mathrm{L}^{1}\right]$ & $3.0 \pm 0.9$ & $5.0 \pm 0.4$ \\
$\left.\mathrm{~L}^{3}(\mathrm{OEt}) \mathrm{Ti}-\mathrm{O}-\mathrm{Ti}(\mathrm{OEt}) \mathrm{L}^{3}\right]$ & $19.3 \pm 2.0$ & $20.8 \pm 2.3$ \\
Cisplatin $^{3}$ & $1.2 \pm 0.4$ & $3.0 \pm 1.3$ \\
\hline
\end{tabular}

a Cisplatin served as the reference compound in all assays.

certainly doubtful. However, the characterized dinuclear complexes represent the first of their kind tested in biological assays and it is yet not clear if other salan complexes behave in a similar manner. Moreover, further research efforts are required to answer the question if such dinuclear complexes might form under biological conditions.

In summary, herein we report the synthesis of mononuclear, methoxy substituted titanium salan complexes. Their controlled hydrolysis afforded $\mu$-oxo bridged dinuclear complexes in good yields still bearing one labile alkoxy ligand at each metal center. These partially hydrolyzed dinuclear complexes are the first of their kind to display a high degree of cytotoxicity when tested in two different human cancer cell lines.

\section{Abbreviations}

COSY correlation spectroscopy

Cp $\quad \eta^{5}$-cyclopentadienyl

DMEM Dulbecco's Modified Eagle Medium

ECACC European Collection of Cell Cultures

Hbzac benzoylacetone = phenylbutane-1,3-dione

Hela S3 human cervix adenocarcinoma cell-line - ECACC No. 87110901

Hep G2 human hepatocyte carcinoma - ECACC No. 85011430

HMBC heteronuclear multiple-bond correlation

HSQC heteronuclear single quantum coherence

ORTEP Oak Ridge Thermal Ellipsoid Plot Program

THF tetrahydrofurane

TMS tetramethylsilane

\section{Acknowledgments}

We gratefully acknowledge financial and scientific support from the Konstanz Research School Chemical Biology (KoRS-CB). T.A.I. thanks the KoRS-CB for a personal scholarship. The authors would like to express their gratitude to Malin Bein for help with the biological assays and to Anke Friemel for recording the time-resolved and 2D-NMR spectroscopy data.

\section{References}

[1] H. Köpf, P. Köpf-Maier, Angewandte Chemie (International Ed. in English) 18 (1979) $477-478$

[2] P. Köpf-Maier, F. Preiss, T. Marx, T. Klapötke, H. Köpf, Anticancer Research 6 (1986) 33-37

[3] N.J. Sweeney, O. Mendoza, H. Müller-Bunz, C. Pampillón, F.-J.K. Rehmann, K. Strohfeldt, M. Tacke, Journal of Organometallic Chemistry 690 (2005) 4537-4544.

[4] P.M. Abeysinghe, M.M. Harding, Dalton Transactions (2007) 3474-3482.

[5] K. Strohfeldt, M. Tacke, Chemical Society Reviews 37 (2008) 1174-1187.

[6] F. Caruso, M. Rossi, J. Tanski, R. Sartori, R. Sariego, S. Moya, S. Diez, E. Navarrete, A Cingolani, F. Marchetti, C. Pettinari, Journal of Medicinal Chemistry 43 (2000) Cingolani,

[7] T. Schilling, K.B. Keppler, M.E. Heim, G. Niebch, H. Dietzfelbinger, J. Rastetter, A.R. Hanauske, Investigational New Drugs 13 (1996) 327-332. 
[8] H. Bischoff, M.R. Berger, B.K. Keppler, D. Schmähl, Journal of Cancer Research and Clinical Oncology 113 (1987) 446-450.

[9] E.Y. Tshuva, D. Peri, Coordination Chemistry Reviews 253 (2009) 2098-2115.

10] E.Y. Tshuva, J.A. Ashenhurst, European Journal of Inorganic Chemistry 15 (2009) 2203-2218.

[11] T.A. Immel, M. Debiak, U. Groth, A. Bürkle, T. Huhn, ChemMedChem 4 (2009) 738-741.

[12] J.H. Toney, T.J. Marks, Journal of the American Chemical Society 107 (1985) 947-953.

[13] H. Köpf, S. Grabowski, R. Voigtländer, Journal of Organometallic Chemistry 216 (1981) 185-190.

[14] T.A. Immel, U. Groth, T. Huhn, Chemistry A European Journal 16 (2010) 2775-2789.

[15] D. Peri, S. Meker, M. Shavit, E.Y. Tshuva, Chemistry A European Journal 15 (2009) 2403-2415.

[16] D. Peri, S. Meker, C.M. Manna, E.Y. Tshuva, Inorganic Chemistry 50 (2011) 1030-1038.

[17] A.J. Nielson, J.M. Waters, Polyhedron 29 (2010) 1715-1726.

[18] W.L.F. Armarego, C.L.L. Chai, Purification of Laboratory Chemicals, 5th ed. Elsevier Science, 2003.

[19] I. Correia, J.C. Pessoa, M.T. Duarte, M.F.M. da Piedade, T. Jackush, T. Kiss, M.M.C.A. Castro, C.F.G.C. Geraldes, F. Avecilla, European Journal of Inorganic Chemistry 11 (2005) 732-744.

[20] P.E. Aranha, M.P. dos Santos, S. Romera, E.R. Dockal, Polyhedron 26 (2007) 1373-1382.

[21] S.R. Doctrow, K. Huffman, C.B. Marcus, G. Tocco, E. Malfroy, C.A. Adinolfi, H. Kruk, K. Baker, N. Lazarowych, J. Mascarenhas, B. Malfroyt, Journal of Medicinal Chemistry 45 (2002) $4549-4558$
22] B. Schweder, D. Walther, T. Dohler, O. Klobes, H. Gorls, Journal für Praktische Chemie 341 (1999) 736-747.

[23] M.J. Caulfield, T. Russo, D.H. Solomon, Australian Journal of Chemistry 53 (2000) $545-549$

[24] C.J. Whiteoak, G.J.P. Britovsek, V.C. Gibson, A.J.P. White, Dalton Transactions (2009) 2337-2344.

[25] Stoe \& Cie GMBH, IPDS Software, Darmstadt, Germany, 1996.

[26] G.M. Sheldrick, SHELX-97, University of Göttingen, Göttingen, 1997.

27] A. Altomare, M.C. Burla, M. Camalli, G.L. Cascarano, C. Giacovazzo, A. Guagliardi, A.G.G. Moliterni, G. Polidori, R. Spagna, Journal of Applied Crystallography 32 (1999) 115-119.

[28] L.J. Farrugia, Journal of Applied Crystallography 32 (1999) 837-838

[29] L.J. Farrugia, ORTEP-III for Windows, Journal of Applied Crystallography 30 (1997) 565.

30] A.L. Spek, Journal of Applied Crystallography 36 (2003) 7-13.

[31] R.D. Fields, M.V. Lancaster, American Biotechnology Laboratory 11 (1993) 48-49.

32] R. Hamid, Y. Rotshteyn, L. Rabadi, R. Parikh, P. Bullock, Toxicology in Vitro 18 (2004) 703-710.

[33] Systat Software, Inc. 2006 (http://www.systat.com)

[34] J. Balsells, P.J. Carroll, P. Walsh, Journal of Inorganic Chemistry 40 (2001) $5568-5574$

[35] S. Gendler, S. Segal, I. Goldberg, Z. Goldschmidt, M. Kol, Inorganic Chemistry 45 (2006) 4783-4790.

[36] M. Shavit, D. Peri, C.M. Manna, J.S. Alexander, E.Y. Tshuva, Journal of the American Chemical Society 129 (2007) 12098-12099. 
Supplemental Information for the manuscript

Cytotoxic Dinuclear Titanium-Salan Complexes: Structural and Biological Characterization

Timo A. Immel, ${ }^{\text {[a] }}$ Martin Grützke, ${ }^{\text {[a] }}$ Ellen Batroff, ${ }^{\text {[a] }}$ Ulrich Groth ${ }^{\text {[a] }}$ and Thomas Huhn* [a]

[a] Fachbereich Chemie and Konstanz Research School Chemical Biology, Universität Konstanz, Universitätsstraße 10, Fach 720, 78457 Konstanz (Germany).

[*] Tel.: +497531882283; fax: +497531884424 .

E-mail address: thomas.huhn@uni-konstanz.de (Th.Huhn) 


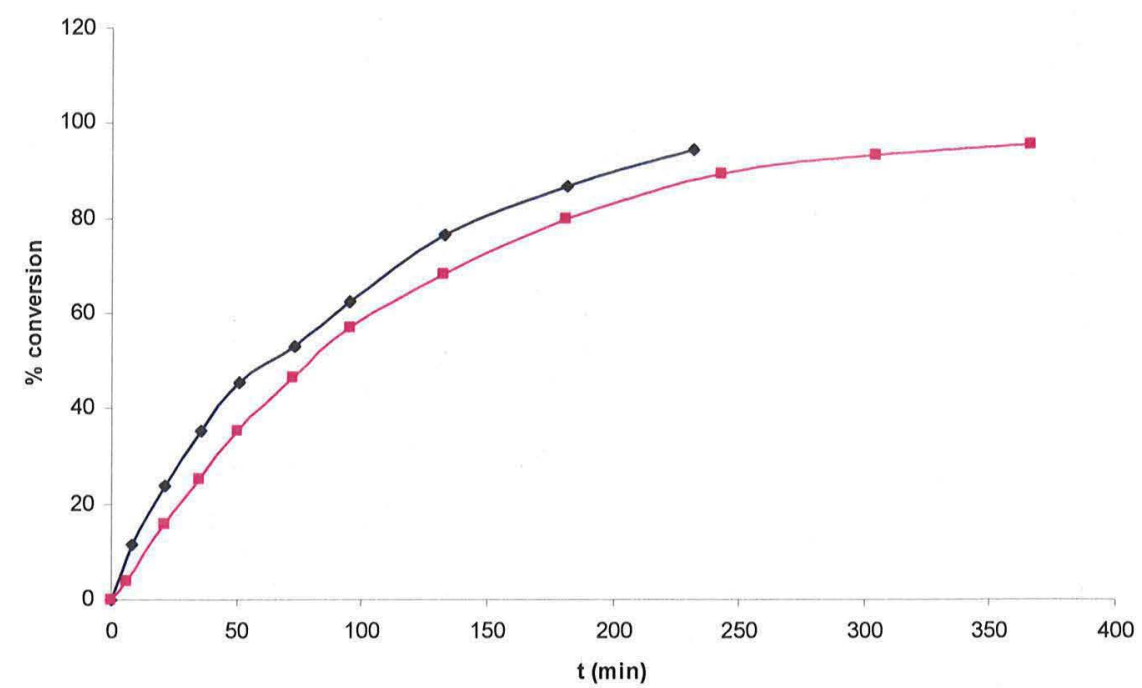

Figure S1: Plots of hydrolysis vs. reaction time of mononuclear $\left[\mathrm{TiL}^{1}(\mathrm{OEt})_{2}\right](\star)$ and $\left[\mathrm{TiL}^{3}(\mathrm{OEt})_{2}\right](\varpi)$. Data acquired by time resolved ${ }^{1} \mathrm{H}-\mathrm{NMR}$ at $37^{\circ} \mathrm{C}$. Values gathered by analyzing the decrease of isolated signals of the titanium bound salan backbone and the increase of the liberated alkoxy ligands signals. Integrals are normalized against internal standard.

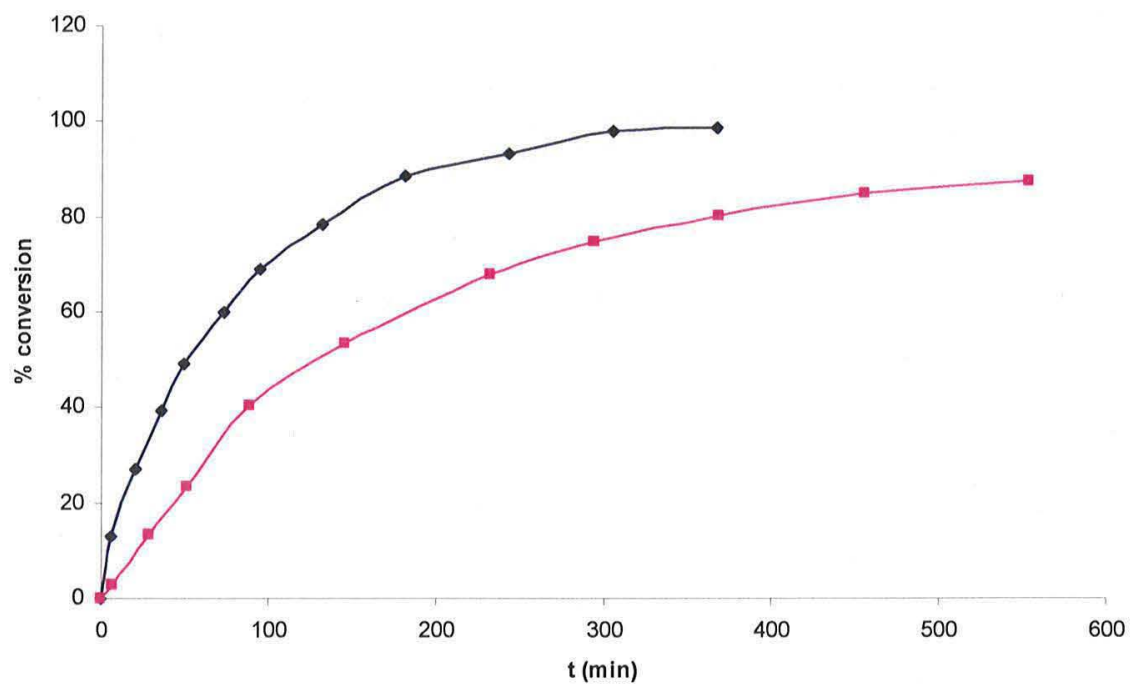

Figure S2: Plots of hydrolysis vs. reaction time of dinuclear $\left[\mathrm{L}^{1}(\mathrm{OEt}) \mathrm{Ti}-\mathrm{O}-\mathrm{Ti}(\mathrm{OEt}) \mathrm{L}^{1}\right](\downarrow)$ and $\left[\mathrm{L}^{3}(\mathrm{OEt}) \mathrm{Ti}-\right.$ $\left.\mathrm{O}-\mathrm{Ti}(\mathrm{OEt}) \mathrm{L}^{3}\right]$ ( ${ }^{\mathrm{w}}$ ). Data acquired by time resolved ${ }^{1} \mathrm{H}-\mathrm{NMR}$ at $37{ }^{\circ} \mathrm{C}$. Values gathered by analyzing the decrease of isolated signals of the titanium bound salan backbone and the increase of the liberated alkoxy ligands signals. Integrals are normalized against internal standard. 


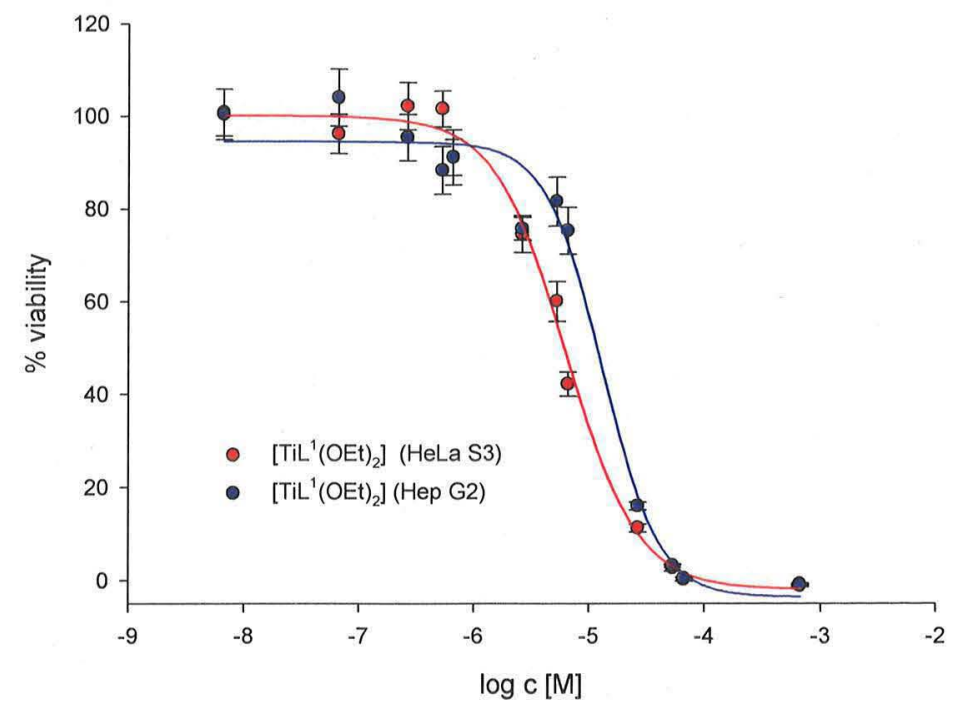

Figure S3. Loss of viability of HeLa S3 (red) and Hep G2 (blue) cells as a function of treatment with different concentrations of mononuclear $\left[\mathrm{TiL}^{1}(\mathrm{OEt})_{2}\right]$ after $48 \mathrm{~h}$ of incubation.

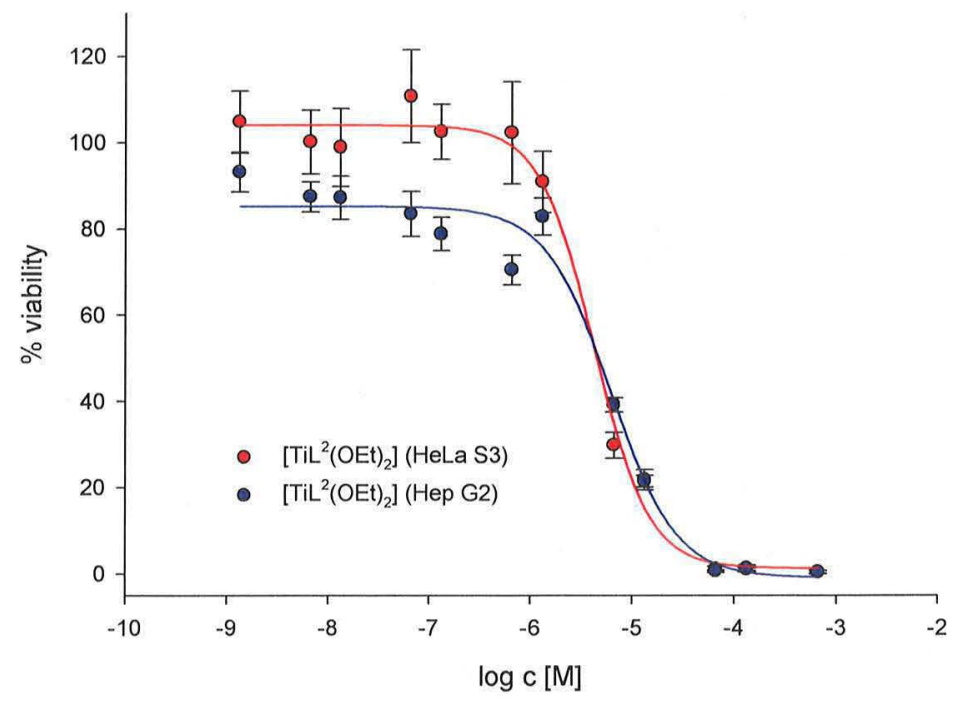

Figure S4. Loss of viability of HeLa S3 (red) and Hep G2 (blue) cells as a function of treatment with different concentrations of mononuclear $\left[\mathrm{TiL}^{2}(\mathrm{OEt})_{2}\right]$ after $48 \mathrm{~h}$ of incubation. 


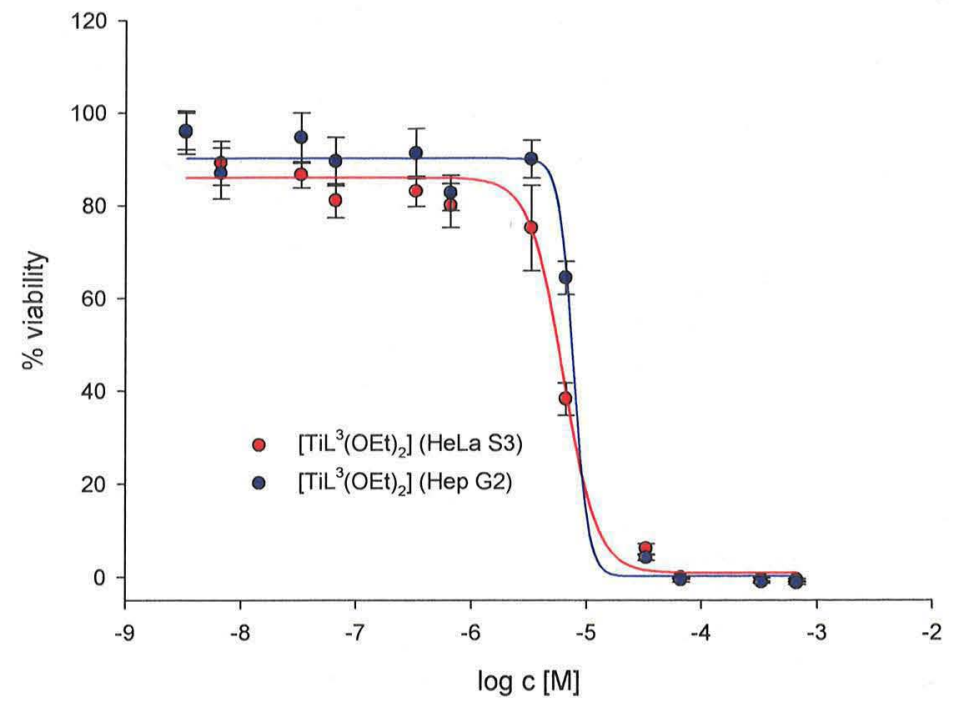

Figure S5. Loss of viability of HeLa S3 (red) and Hep G2 (blue) cells as a function of treatment with different concentrations of mononuclear $\left[\mathrm{TiL}^{3}(\mathrm{OEt})_{2}\right]$ after $48 \mathrm{~h}$ of incubation.

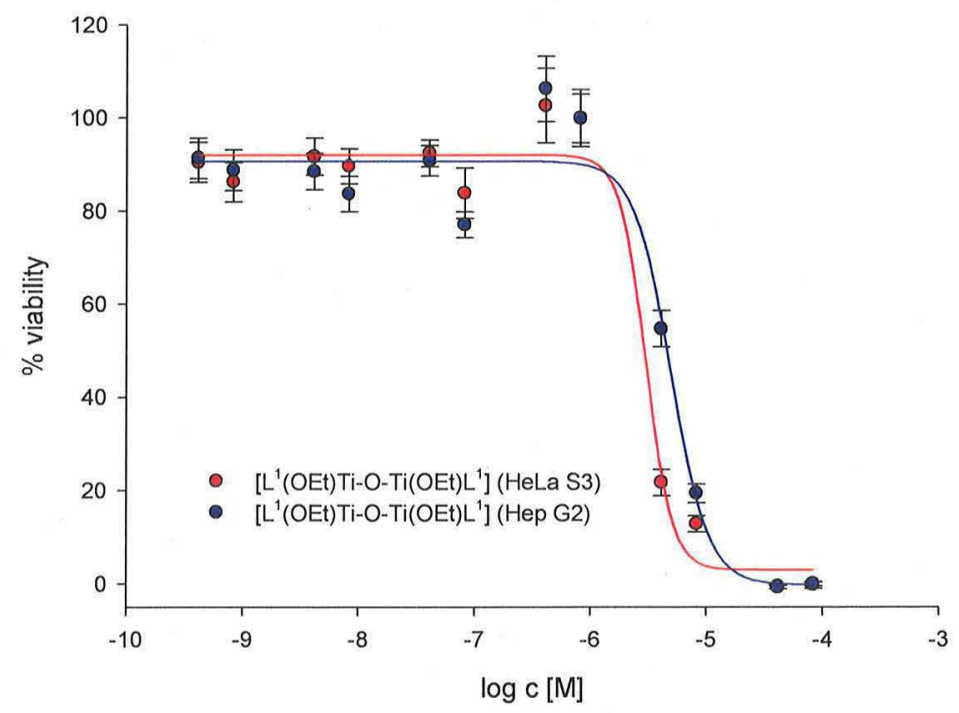

Figure S6. Loss of viability of HeLa S3 (red) and Hep G2 (blue) cells as a function of treatment with different concentrations of dinuclear $\left[\mathrm{L}^{1}(\mathrm{OEt}) \mathrm{Ti}-\mathrm{O}-\mathrm{Ti}(\mathrm{OEt}) \mathrm{L}^{1}\right]$ after $48 \mathrm{~h}$ of incubation. 


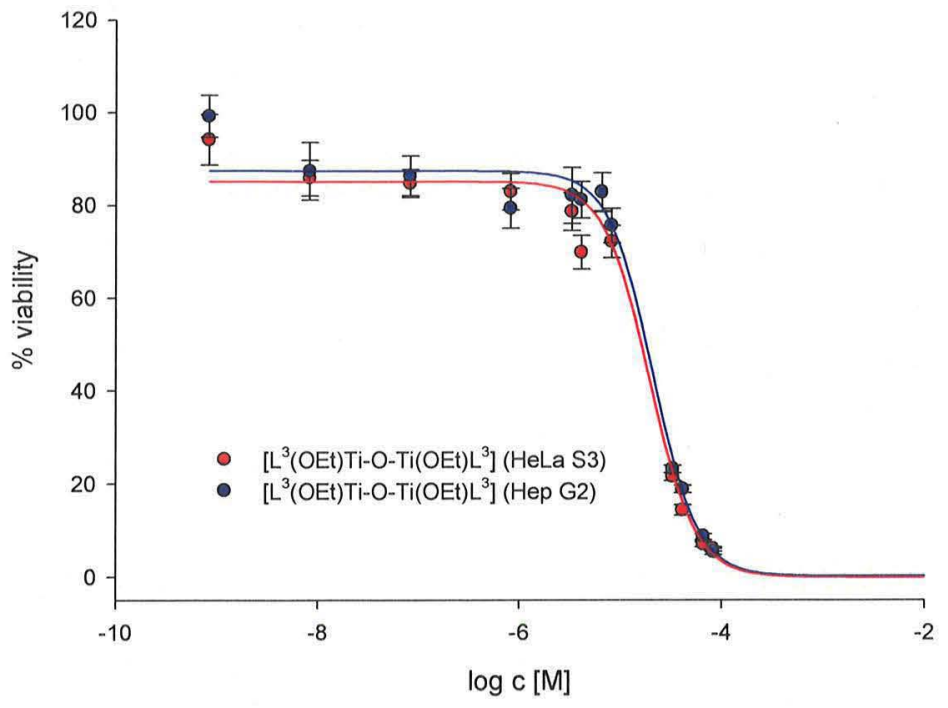

Figure S7. Loss of viability of HeLa S3 (red) and Hep G2 (blue) cells as a function of treatment with different concentrations of dinuclear $\left[\mathrm{L}^{3}(\mathrm{OEt}) \mathrm{Ti}-\mathrm{O}-\mathrm{Ti}(\mathrm{OEt}) \mathrm{L}^{3}\right]$ after $48 \mathrm{~h}$ of incubation. 